\title{
miR-149* Suppresses Liver Cancer Progression by Down-Regulating Tumor Necrosis Factor Receptor 1-Associated Death Domain Protein Expression
}

\author{
Qingqing Feng, ${ }^{*}$ Hongli Zhang, ${ }^{*}$ Xiaobo Nie, ${ }^{\dagger}$ Yuanqiang Li, ${ }^{*}$ Wei-Dong Chen, ${ }^{\dagger \dagger}$ and Yan-Dong Wang ${ }^{*}$
}

\begin{abstract}
From the State Key Laboratory of Chemical Resource Engineering, * College of Life Science and Technology, Beijing University of Chemical Technology, Beijing; the Key Laboratory of Receptors-Mediated Gene Regulation and Drug Discovery, ${ }^{\dagger}$ School of Medicine, Henan University, Kaifeng; and the Key Laboratory of Molecular Pathology, ${ }^{\ddagger}$ School of Basic Medical Science, Inner Mongolia Medical University, Hohhot, PR China
\end{abstract}

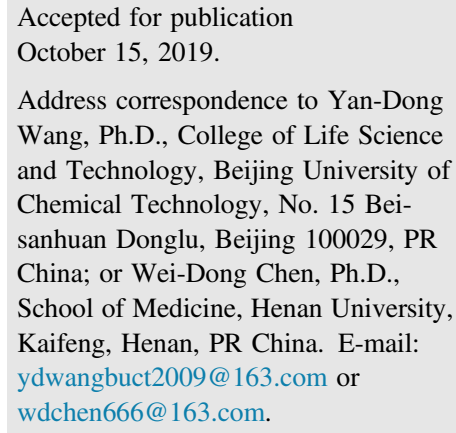

Liver cancer is the third leading cause of cancer-related death worldwide. Herein, we show that miR-149* serves as a novel tumor suppressor for liver tumorigenesis. Mice with genetic deletion of miR-149* (miR-149*-/- mice), which caused loss of both miR-149 and miR-149*, were considerably more susceptible to acute liver injury and hepatic carcinogenesis induced by diethylnitrosamine than wild-type mice, accompanied by increased compensatory proliferation and up-regulated gene expression of certain inflammatory cytokines. miR-149* mimics dramatically impaired liver cancer cell proliferation and migration in vitro and blocked liver cancer progression in a xenograft model. Furthermore, miR-149* strongly suppressed NF- $\kappa \mathrm{B}$ signaling and repressed tumor necrosis factor receptor type 1-associated death domain protein expression in the NF- $\kappa \mathrm{B}$ signaling pathway. These results reveal that miR-149*, as a novel liver tumor suppressor, may serve as a potential therapeutic target for liver cancer treatment. (Am J Pathol 2020, 190: 469-483; https://doi.org/10.1016/j.ajpath.2019.10.010)
Hepatocellular carcinoma (HCC), developing almost completely in the context of chronic liver diseases, is a prototypical inflammation-associated cancer. ${ }^{1,2}$ It is the most common type of primary liver cancer. Liver cancer represents the third leading cause of cancer death worldwide. $^{3}$ The therapeutic efficacy and prognosis of HCC is limited $\left(788,000\right.$ deaths occurred worldwide every year). ${ }^{4}$ Thus, it was urgent and essential to explore the mechanisms of HCC and identify novel therapeutic targets for prediction or treatment of liver cancer.

$\mathrm{NF}-\kappa \mathrm{B}$ is quiescent in normal tissue, whereas it is activated in a variety of inflammatory diseases and tumors. The NF- $\kappa \mathrm{B}$ pathway has typically been related to mediation of inflammation and cancer. ${ }^{5}$ The previous reports indicate that the I $\mathrm{B} \alpha$ kinase-dependent NF- $\kappa \mathrm{B}$ activation pathway plays essential roles in tumor promotion. ${ }^{6,7}$ In response to inflammatory stimuli, such as lipopolysaccharide (LPS), tumor necrosis factor- $\alpha$ (TNF- $\alpha$ ), double-stranded RNA, or $\mathrm{UV}$ radiation, NF- $\kappa \mathrm{B}$ is rapidly posttranslational triggered and $\mathrm{I} \kappa \mathrm{B} \alpha$ is phosphorylated by $\mathrm{I} \kappa \mathrm{B} \alpha$ kinase, leading to polyubiquitination and degradation by proteasomes. Then, it leads to nuclear translocation of canonical NF- $\kappa \mathrm{B}$ members [p65 (RelA) and p50 heterodimer] and activation of its target genes. Mounting evidence has revealed that NF- $\kappa \mathrm{B}$

\footnotetext{
Supported by the National Natural Science Foundation of China grants 81672433 (Y.-D.W.), $81970551 \quad$ (Y.-D.W.), 81370537 (Y.-D.W.), 81970726 (W.-D.C.), and 81472232 (W.-D.C.); the Fundamental Research Funds for the Central Universities and research projects on biomedical transformation of China-Japan Friendship Hospital grant PYBZ1803 (Y.-D.W.); Henan Provincial Natural Science Foundation grants 182300410323 and 182300410316; Program for Science and Technology Innovation Talents in Universities of Henan Province (HASTIT) grant 13HASTIT024; and Plan for Scientific Innovation Talent of Henan Province (W.-D.C.)

Disclosures: None declared.
} 
inhibition is able to diminish tumorigenesis process in multiple mouse models. ${ }^{8-10}$ Thus, discovering novel therapeutic targets that block NF- $\kappa \mathrm{B}$ activation would be valuable for repressing prolonged activation of this signal in tumor development and then developing novel appropriate therapeutic strategies for cancer.

miRNAs are short (approximately 18 to $25 \mathrm{bp}$ ) and noncoding RNAs. miRNAs can negatively modulate gene transcription through binding to complementary regions of target mRNAs. ${ }^{11-13}$ Functional studies in patients and animal models of liver cancer have identified the indispensable roles of miRNAs that may serve as cancer drivers or tumor suppressor in the occurrence and development of liver carcinogenesis. ${ }^{14,15}$ For example, Fang et al ${ }^{16}$ described that secreted miR-103 aggravated metastasis and vascular permeability in HCC and hence it may be of prognostic or therapeutic value for HCC metastasis. Kabir et $\mathrm{al}^{17}$ reported that miR-7 prevents proliferation and invasiveness in sorafenib-resistant HCC via directly inhibiting tyrosine receptor kinase 3 (TYRO3) and may be considered as a promising RNA-based therapeutic therapy. $\mathrm{Wu}$ et $\mathrm{al}^{18}$ identified a valuable role for miR-206 as a therapeutic potential target to treat hepatocarcinogenesis by modulating expression of c-met, cyclin D1, and cyclin-dependent kinase 6. Several publications have reported functional cross talk between numerous miRNAs and NF- $\kappa \mathrm{B}$, including miR224, miR-124-3p, miR-let-7a, miR-181d, and others. It has been suggested that the interaction between NF- $\kappa \mathrm{B}$ and miRNAs has different physiological significance in inflammation and cancer. ${ }^{8,19-22}$

miRNA primary transcripts are cleaved through the action of Dicer to generate double-stranded miRNA duplexes. One strand serves as a mature miRNA, whereas the complementary strand (miRNA*) of the duplex is always degraded shortly. ${ }^{23}$ Many reports reveal that most of miRNA*s are ephemeral and ineffective. However, part of them is also functional in mediating gene regulation as the mature miRNAs do. ${ }^{24}$ The previous reports recognized miR-149 as an essential suppressor in colorectal cancer and HCC, including regulation of metastasis and inflammatory response. ${ }^{25,26}$ However, the biological significance of the down-regulation of miR-149* expression in diseases at the molecular level has not yet been fully elucidated. ${ }^{13,23,27}$ Our recent publication supports a role for miR-149* in liver inflammation by negatively regulating STAT3-mediated cell signaling. ${ }^{13}$ There has been growing evidence support that this chronic inflammation is a common origin of pathogenesis of hepatocellular carcinoma. ${ }^{2}$ Blocking STAT3 signaling dramatically suppresses liver tumor progression. ${ }^{28,29}$ Thus, our previous report raises the high possibility that miR-149* may have the potential to suppress inflammation-associated liver carcinogenesis.

In the present research, genetic deletion of miR-149* (miR$149^{*^{-1-}}$ mice) is more susceptible to diethylnitrosamine (DEN)-induced hepatocellular carcinogenesis, and miR-149* mimics dramatically impaired $\mathrm{HCC}$ cell growth and migration and suppressed liver cancer progression in a xenograft model. In addition, we reveal that miR-149* inhibits NF-אB signaling and can repress tumor necrosis factor receptor 1 -associated death domain (TRADD) protein expression in the NF- $\kappa \mathrm{B}$ signaling pathway. These data imply miR-149* may be a promising and valuable target for human liver cancer treatment by antagonizing NF- $\kappa \mathrm{B}$ signaling.

\section{Materials and Methods}

\section{Animals}

miR-149* ${ }^{-/-}$mice were generated with a C57BL/6 background, as described previously. ${ }^{13}$ Wild-type (WT) C57B1/6 mice were purchased from Beijing Experimental Animal Center [Beijing, China; license number SCXK (Jing) 20020003]. All experiments followed the NIH Guide for the Care and Use of Laboratory Animals. ${ }^{30}$

For initiating DEN-induced acute hepatic injury responses, WT and miR-149* ${ }^{-1-}$ males at 4 weeks of age were intraperitoneally injected with a single dose of 100 $\mathrm{mg} / \mathrm{kg}$ (body weight) DEN (Sigma, St. Louis, MO). At 48 hours after DEN exposure, mice were sacrificed, and serum was separated and analyzed within 48 hours.

To induce HCC, 20-day-old WT and miR-149*-/- male mice were intraperitoneally injected with a single dose of 25 $\mathrm{mg} / \mathrm{kg}$ (body weight) DEN. At 8 months after DEN exposure, mice were sacrificed.

The administration of LPS (St. Louis, MO) and miRNA agomir (Ribo-bio, Guangzhou, China) was performed, as previously described. ${ }^{13} \mathrm{WT}$ and $\mathrm{miR}-149^{*^{-/-}}$male siblings at 8 weeks of age were fasted overnight, LPS $(10 \mathrm{mg} / \mathrm{kg}$ body weight) was administrated intraperitoneally, and then they were fed water ad libitum. After 6 hours of LPS treatment, mice were sacrificed.

For miRNA agomir treatment, WT male siblings at 8 weeks of age were randomly grouped into miR-149* and miRNA negative control. And $2 \mu \mathrm{mol} / \mathrm{kg} \mathrm{miR}-149^{*}$ agomir (body weight) or control agomir was administrated with a tail vein injection for 48 hours.

Knockout male siblings at 8 weeks of age were randomly grouped into miR-149 and miRNA negative control. And 2 $\mu \mathrm{mol} / \mathrm{kg}$ agomir (body weight) was administrated with a tail vein injection for 24 hours. Then, mice were intraperitoneally injected with the $150 \mathrm{mg} / \mathrm{kg}$ (body weight) DEN. At 48 hours after DEN exposure, mice were sacrificed, and serum was separated and analyzed within 48 hours. And, miScript II RT Kit (Qiagen, Hilden, Germany; 218161) and miScript SYBR Green PCR Kit (Qiagen; 218073) were used to detect miR-149 and miR-149* content.

For in vivo tumorigenesis assay, $2.5 \times 10^{6}$ cells/well were preplated into $10-\mathrm{cm}$ plates and were transfected with miRNA mimics. Cells were transfected for 24 hours before implantation. Finally, cells were collected and resuspended in precooled phosphate-buffered saline. Male BALB-C nude mice (4 weeks of age) were each injected subcutaneously in 
Table 1 Primers for PCR

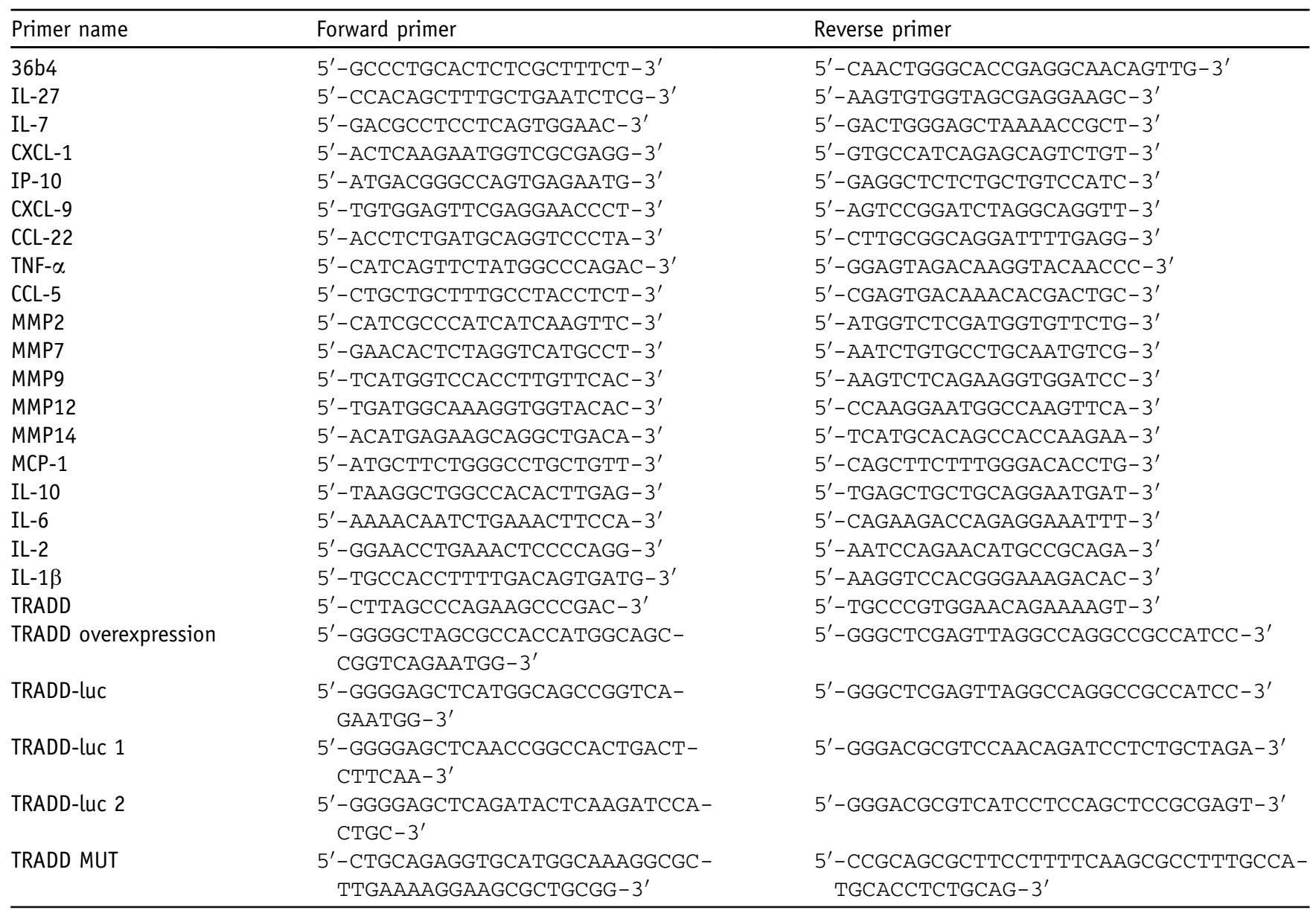

CCL, chemokine (C-C motif) ligand; IP-10, interferon- $\gamma$-induced protein 10; luc, luciferase; MCP-1, monocyte chemoattractant protein-1; MUT, mutation; TNF- $\alpha$, tumor necrosis factor- $\alpha$.

the left forelimb armpit with negative control (NC) mimics or miR-149* mimic-transfected Hepa1-6 cells $\left(3 \times 10^{6}\right.$ cells per mouse; $n=5$ ) in a total volume of $150 \mu \mathrm{L}$. Tumor growth was evaluated with a caliper by measuring tumor length and width every other day, and tumor volume was calculated according to $1 / 2 \times$ (length $\times$ width). ${ }^{2}$ The mice were sacrificed after 11 days, and the tumors were removed and weighed.

\section{Cell Culture and Transient Transfection}

miRNA mimics and siRNAs were purchased from Guangzhou RiboBio (Guangzhou, China). Mouse Hepa1-6 cells were grown in Dulbecco's modified essential medium (with L-glutamine) with $10 \%$ fetal bovine serum and $1 \%$ penicillinstreptomycin. A total of $1 \times 10^{6}$ cells/well were preplated into 6-well plates and were transfected with miRNA mimics $(50 \mathrm{nmol} / \mathrm{L})$ or siRNA mimics $(50 \mathrm{nmol} / \mathrm{L})$ using Lipofectamine 2000 (Invitrogen, Carlsbad, CA). Then, cells were incubated with LPS ( $1 \mu \mathrm{g} / \mathrm{mL}$; Sigma) or TNF- $\alpha(20 \mathrm{ng} / \mathrm{mL}$; PeproTech, Rocky Hill, NJ) for 6 hours and then harvested for RNA extraction. For induction of p65, Hepa1-6 cells were cotransfected with miR-149* mimics $(50 \mathrm{nmol} / \mathrm{L})$ or $\mathrm{NC}$ mimics and p65 expression plasmid ( $200 \mathrm{ng} / \mathrm{mL})$. After 24 hours, cells were harvested for RNA extraction and real-time quantitative PCR analysis.

Mouse NCTC 1469 cells were grown in Dulbecco's modified essential medium (with L-glutamine) with $10 \%$ horse serum and $1 \%$ penicillin-streptomycin. A total of $1 \times 10^{6}$ cells/ well were preplated into 6-well plates and were transfected with miRNA mimics $(50 \mathrm{nmol} / \mathrm{L})$ or siRNA mimics $(50 \mathrm{nmol} /$ L) using Hiperfect transfection reagent (Qiagen).

For TRADD overexpression, the open reading frame of TRADD was amplified by PCR and the PCR products of TRADD open reading frame were inserted into the restriction sites of the pcDNA3.1 vector. A total of $900 \mathrm{ng} / \mathrm{well}$ of TRADD plasmid was cotransfected with miRNA mimics into Hepa1-6 cells. Finally, cells were collected for RNA extraction and TRADD mRNA expression level test.

\section{Cell Proliferation Assay}

Cell proliferation of NCTC 1469 was assessed by MTT assay. After transfection for 24 hours, cells were seeded into 96-well plates with four parallel wells in one group. The cell proliferation was examined every 24 hours. The number of 


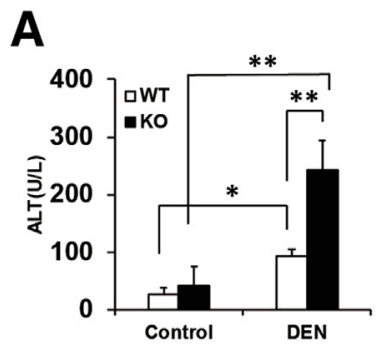

B

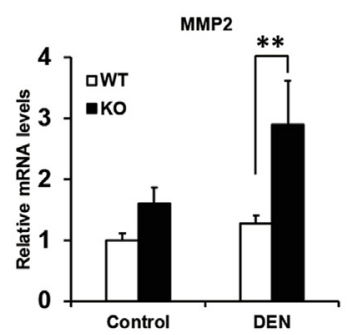

C

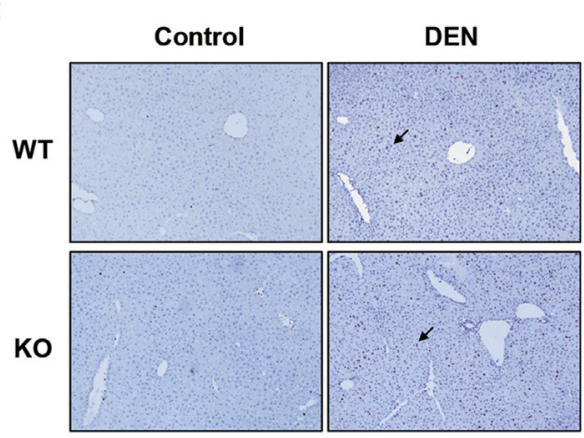

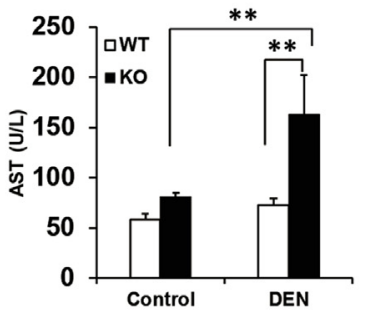
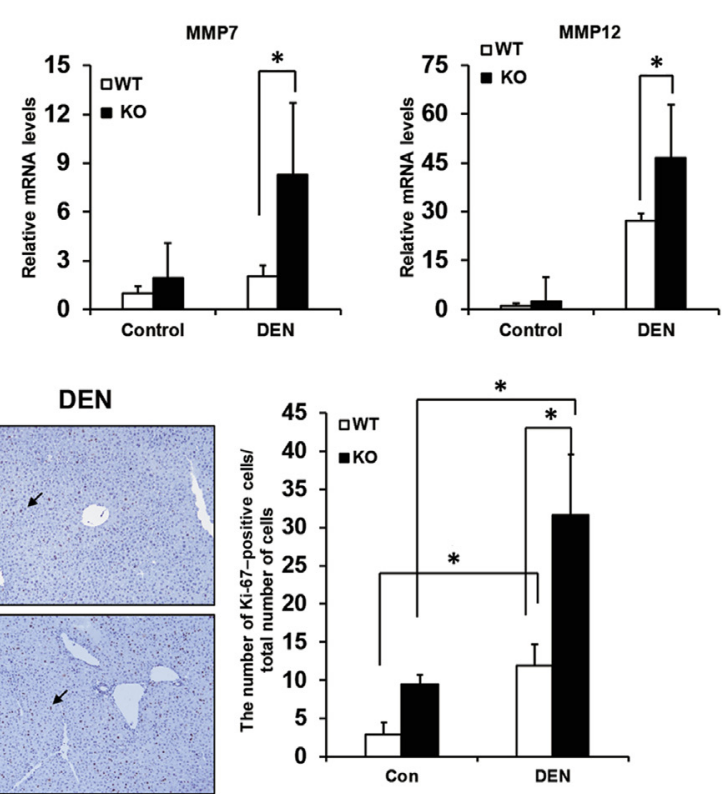

Figure 1 miR-149*-/- $[$ nnockout (K0)] mouse livers are more sensitive to diethylnitrosamine (DEN)-induced acute liver injury. A: The amounts of serum alanine transaminase (ALT) and aspartate aminotransferase (AST) were quantified after DEN administration for 48 hours. B: Relative mRNA levels of proinflammatory genes in mice liver were tested by real-time quantitative PCR. C: Representative Ki-67 images of murine liver sections and the number of Ki-67-positive hepatocytes per $\times 20$ high-power field were analyzed in wild-type (WT) and KO livers. Black arrows indicate Ki-67 -positive cells. $n=7$ to 8 (A-C). ${ }^{*} P<0.05$, $* * P<0.01$. Original magnification, $\times 200$. Con, control groups; MMP, matrix metalloproteinase. viable cells was assessed by measurement of the absorbance at $450 \mathrm{~nm}$.

\section{Dual-Luciferase Reporter Assay}

For luciferase assay, Hepa1-6 cells were preplated in 24-well plates and transfected with miRNA mimics or siRNAs, together with the $1000 \mathrm{ng} /$ well NF-KB-luciferase plasmid (provided by Dr. Peter Tontonoz and Dr. Bruce Blumberg, University of California, Los Angeles, Los Angeles, CA) and the $100 \mathrm{ng} /$ well control thymidine kinase driven Renilla luciferase plasmid phRL-TK (provided by Dr. Akio Kruoda, City of Hope, Duarte, CA). phRL-TK was cotransfected for normalization of luciferase value. Eighteen hours after transfection, cells were treated with LPS $(1 \mu \mathrm{g} / \mathrm{mL})$ or TNF- $\alpha$ $(20 \mathrm{ng} / \mathrm{mL})$ for 6 hours. Then, luciferase activity was measured according to instructions of the Dual-Luciferase Reporter Assay System (Promega, Madison, WI). If p65 overexpression plasmid was used for inducing NF- $\kappa \mathrm{B}, 100$ ng/well p65 plasmid (provided by Xufeng Chen, City of Hope) was cotransfected with $50 \mathrm{nmol} / \mathrm{L} \mathrm{miR}-149 *$ mimics or control mimics.

To prove direct targeting by miR-149*, the complete coding sequence (CDS) and two fragments of CDS of TRADD containing putative miR-149*-binding sites were amplified and inserted into the pMIR-Report luciferase vectors, and they were named TRADD-luc, TRADD-luc1, and TRADD-luc2, respectively. And $100 \mathrm{ng} / \mathrm{well}$ of TRADD-luc, TRADD-luc1, and TRADD-luc2 plasmids was transfected separately with $100 \mathrm{ng}$ of phRL-TK and 50 $\mathrm{nmol} / \mathrm{L}$ miRNA mimics. Cells were harvested after 24 hours for the luciferase activity assay.

\section{TRADD Expression of Fluorescence-Activated Cell Sorting Analysis}

TRADD protein was determined by fluorescenceactivated cell sorting analysis, according to the TRADD antibody instructions (Cell Signaling Technology, Danvers, MA; 3694). Cells were collected and resuspended in phosphate-buffered saline and fixed in $4 \%$ formaldehyde for 15 minutes at room temperature. And cells were permeabilized with $90 \%$ methanol for 30 minutes on ice. Cells were washed with phosphate-buffered saline and then cells were immunostained with TRADD antibody at 1:50 for 1 hour at room temperature, and Rabbit (DA1E) mAb IgG XP Isotype Control (Cell Signaling Technology; 3900) was used as isotype control. Cells were washed with $5 \%$ bovine serum albumin and incubated with Anti-Rabbit IgG Alexa Fluor 488 Conjugated antibody (Cell Signaling Technology; 4412) for 30 minutes. Each sample was washed twice with $5 \%$ bovine serum 
A

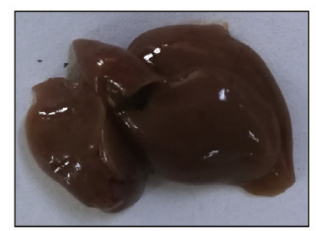

WT

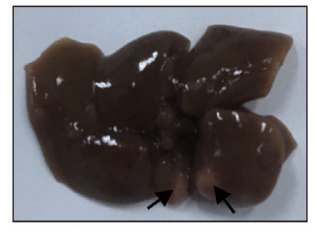

KO
B

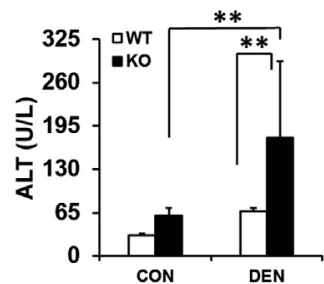

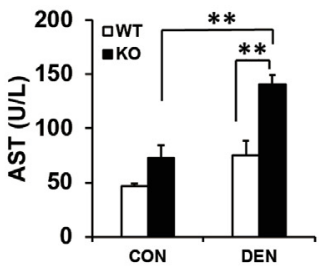

C

WT

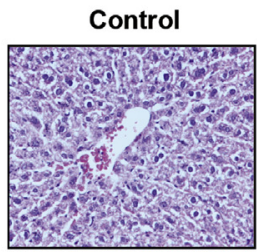

KO

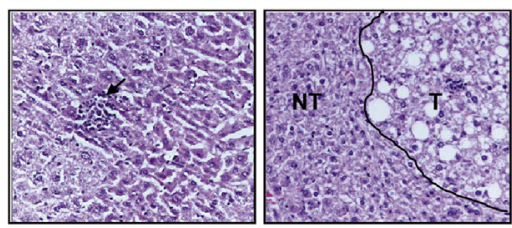

E
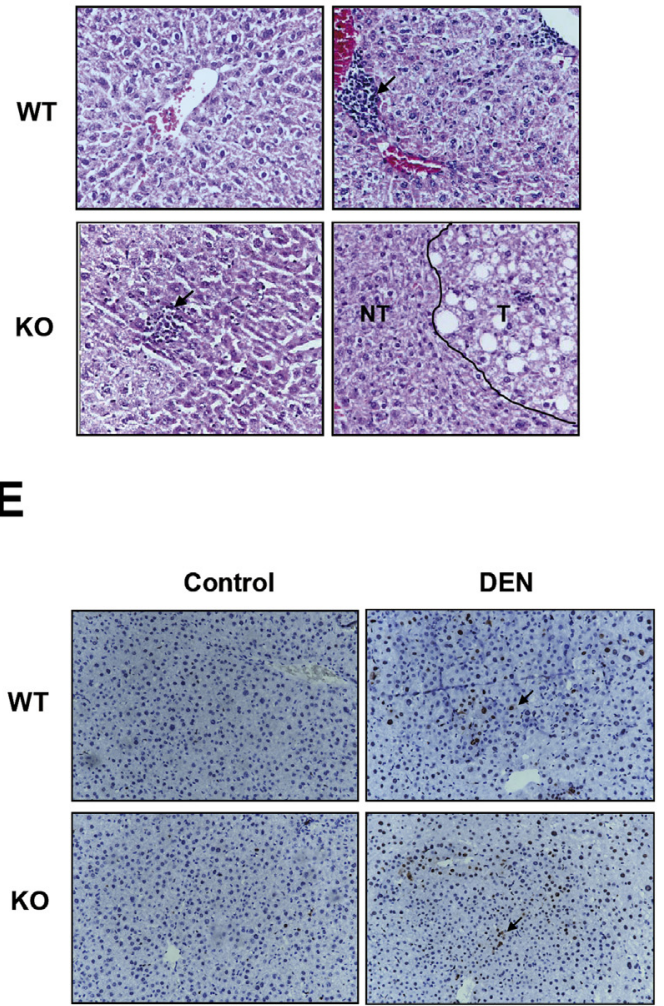

D

WT

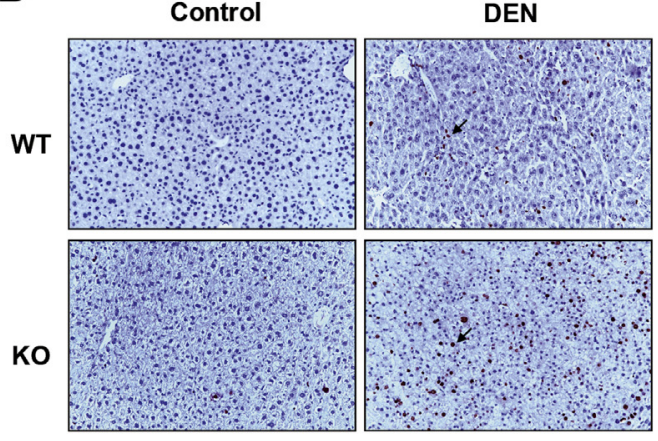

F

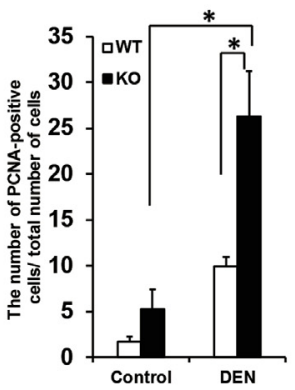

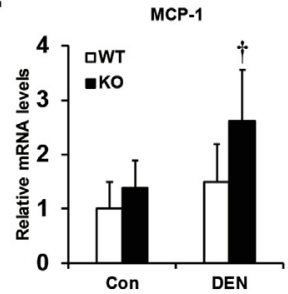

CCL-5

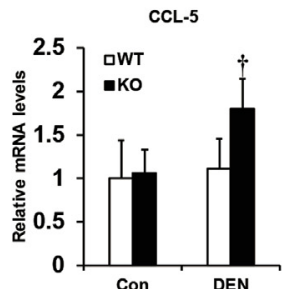

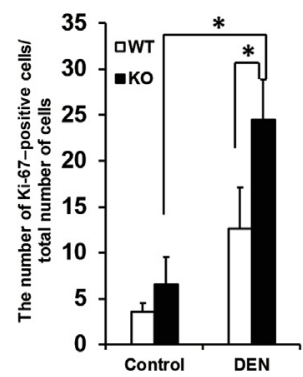

IP-10
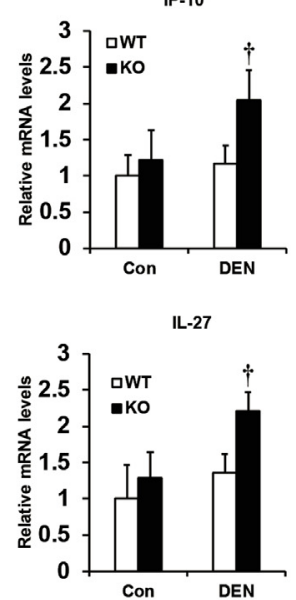

Figure 2 The deficiency of miR-149* promotes diethylnitrosamine (DEN)-induced liver cancer. A: Knockout (K0) mice develop tumors after 8 months of DEN $\left(25 \mathrm{mg} / \mathrm{kg}\right.$ body weight) treatment on the $20^{\text {th }}$ day after birth. Arrows indicate tumors. B: In the DEN-induced hepatocellular carcinoma (HCC) model, the amounts of serum alanine transaminase (ALT) and aspartate aminotransferase (AST) were quantified. C: Representative hematoxylin-eosin staining of liver sections from wild-type (WT) and KO livers in DEN-induced HCC model. Black lines indicate tumor boundaries; arrows, infiltrated inflammatory cells. D: Representative Ki-67 images of murine liver sections and the number analysis of Ki-67-positive hepatocytes per $\times 20$ high-power field in WT and K0 livers. Arrows indicate Ki-67-positive cells. E: Representative proliferating cell nuclear antigen (PCNA) staining of murine liver sections and the number analysis of PCNA-positive hepatocytes. Arrows indicate PCNA-positive cells. F: Relative mRNA levels of proinflammatory genes from WT and miR-149*-1- KO mouse livers after DEN administration. $n=20$ to $25(\mathbf{A}) .{ }^{*} P<0.05,{ }^{*} P<0.01 ;{ }^{\dagger} P<0.05$ versus the DEN-treated WT groups. Original magnification, $\times 200(\mathbf{C}, \mathbf{D}$, and $\mathbf{E})$. CCL, chemokine (C-C motif) ligand; Con, control groups; IP-10, interferon- $\gamma-$ induced protein 10 ; K0, miR-149*-/- mice; NT, nontumor; $T$, tumor.

albumin, resuspended in phosphate-buffered saline, and then analyzed with flow cytometer.

\section{Real-Time Quantitative PCR}

Total RNA was extracted from Hepa1-6 cells and mouse livers with Trizol (Invitrogen, Thermo Fisher Scientific, Carlsbad, CA), and the detailed procedure was performed as described previously. ${ }^{13,31,32}$ Amplification of $\beta$-actin or
36B4 was used as an internal reference for normalization of gene expression. Relative mRNA expression level was described in our results. Primers are shown in Table 1.

\section{Analysis of ALT and AST Activity and Liver Histology}

Alanine transaminase (ALT) and aspartate aminotransferase (AST) activity analysis and hematoxylin and eosin, Ki-67, and proliferating cell nuclear antigen staining were 


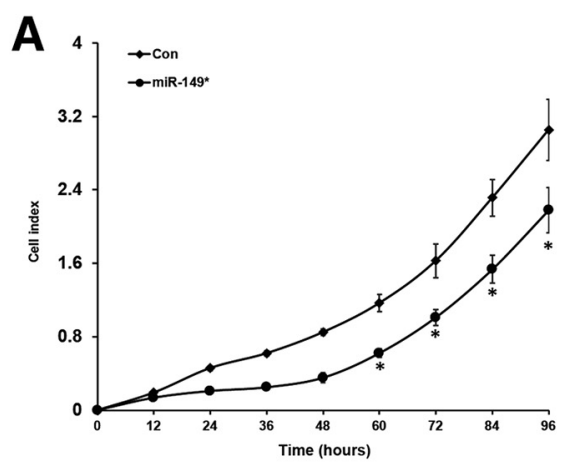

C
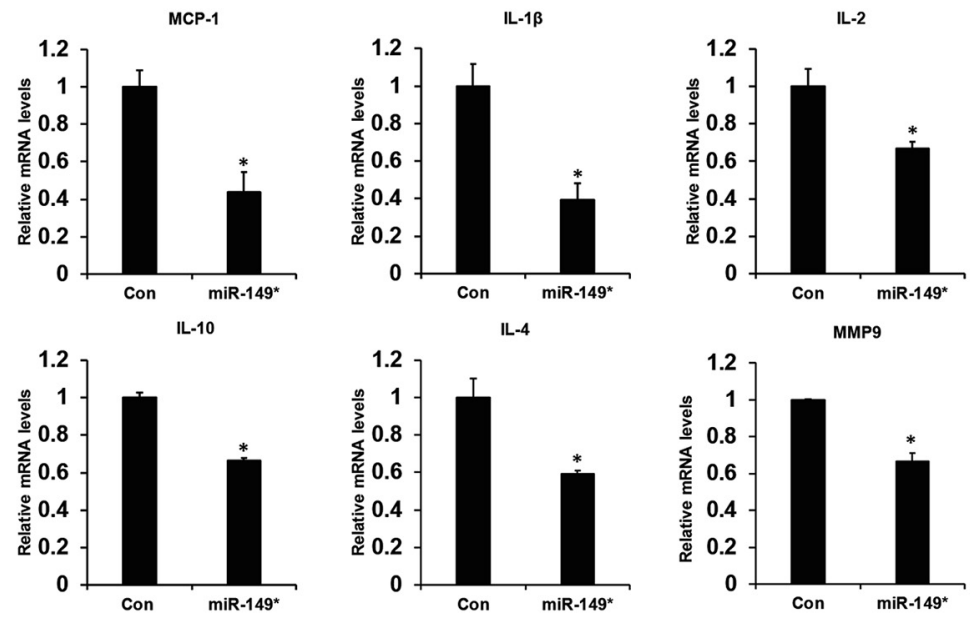

Figure $3 \mathrm{miR}-149^{*}$ mimics impair proliferation and migration of liver cancer cells. A: miR149* mimics inhibit proliferation of Hepa1-6 cells. Proliferation assay was performed using real-time cellular analysis (RTCA). A total of $1 \times 10^{6}$ cells/well were preplated into 6-well plates, and then were transfected with miRNA mimics $(50 \mathrm{nmol} / \mathrm{L})$. Cells were seeded into E-plate $\left(1 \times 10^{5}\right.$ cells/well $)$ at 24 hours after transfection, and RTCA was performed to determine cell proliferation. B: RTCA assay confirms that miR-149* mimics inhibit Hepa1-6 cell migration. A total of $1 \times 10^{6}$ cells/well were preplated into 6-well plates, and then were transfected with miRNA mimics $(50 \mathrm{nmol} / \mathrm{L})$. Then, cells were seeded into CIM Plate (ACEA, San Diego, CA $)\left(1 \times 10^{5}\right.$ cells/well $)$ at 24 hours after transfection, and RTCA was performed to determine cell migration. C: Relative mRNA levels of proinflammatory genes in Hepa1-6 cells. $n=4$ (A and $\mathbf{B}) ; n=3(\mathbf{C}) .{ }^{*} P<0.05$ versus Con. Con, negative control mimics; miR-149*, miR-149* mimics; MMP, matrix metalloproteinase. performed, as previously described. ${ }^{13,31}$ When experiments were terminated and mice were sacrificed, small pieces of liver tissues containing tumors and nontumor areas were fixed in paraformaldehyde and then embedded in paraffin. Then, longitudinal sections ( $3 \mu \mathrm{m}$ thick) were analyzed by hematoxylin and eosin, Ki-67 (antibody from Abcam, Cambridge, UK; catalog number ab15580), and proliferating cell nuclear antigen (antibody from Cell Signaling Technology; catalog Number 13110).

\section{Immunoblot Analysis}

Cells or mouse liver was lysed for protein isolation, and then SDS/PAGE analysis was performed, as described previously. ${ }^{31,33}$ Bands on blots were visualized and protein expression was analyzed with a computerized digital imaging system using Tanon-5200 software (Tanon, Shanghai, China). The primary antibodies used in current research were as follows: $\beta$-actin (Cell Signaling Technology; cata-

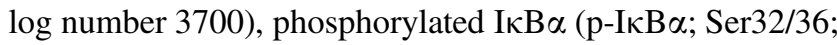
Cell Signaling Technology; catalog number 9246), ІкB $\alpha$ (Cell Signaling Technology; catalog number 9242), phosphorylated STAT3 (Tyr705; Cell Signaling Technology; catalog number 9145), total STAT3 (Cell Signaling Technology; catalog number 4904), and TRADD (Cell Signaling Technology; catalog number 3694).

\section{Statistical Analysis}

All data represent at least three independent experiments and are expressed as the means \pm SEM. The $t$-test and a two-way analysis of variance, followed by Bonferroni's post-hoc test, were performed. $P<0.05$ was considered significant.

\section{Results}

\section{miR-149*-/- Mouse Livers Are More Sensitive to Acute DEN Administration}

First, it was determined whether the genetic deletion of miR$149 *$ affected DEN-induced HCC development. miR-149*-/mice showed a higher susceptibility to DEN-induced acute liver damage than WT mice. DEN-treated miR-149*-I- mice had higher ALT and AST levels (approximately 5.9- and 2.0fold for ALT and AST, respectively) than did the control group of miR-149*--- mice (Figure 1A). WT-DEN mice showed greatly alleviated abnormalities. The expression levels of cell migration-associated genes were detected. MMP2, MMP7, and MMP12 expression levels were induced in the miR-149*-- - DEN group than that in the WT-DEN group (Figure 1B), indicating that these cell migration-related genes were more sensitive to DEN administration in miR-149*-/mouse livers. Next, hepatocyte proliferation was characterized 
A

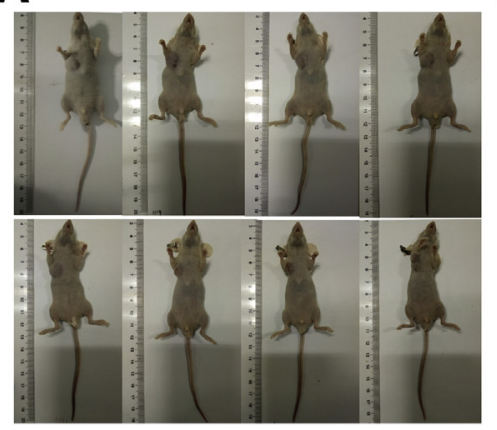

B
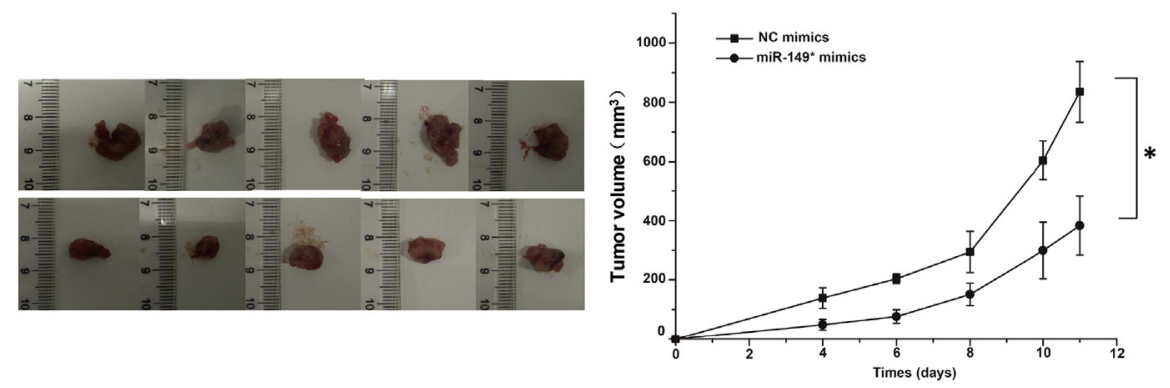

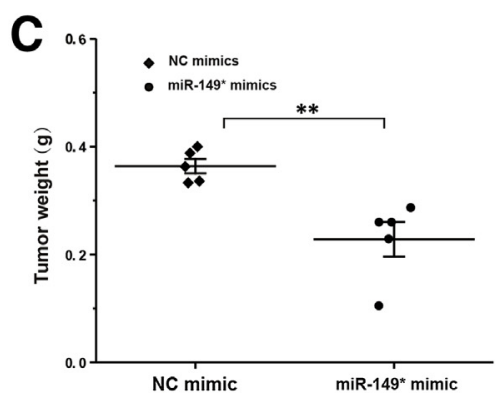

by Ki-67 staining for DEN-administrated mice. miR-149*-/mouse livers showed approximately 2.7 -fold increase in the number of Ki-67-positive cells compared with WT livers after 48 hours' DEN challenge, suggesting that DEN induced higher hepatocyte compensatory proliferation in miR-149*-/- livers than that in WT mouse livers (Figure 1C). Thus, the observed findings indicate that the deficiency of miR-149* was sensitized to DEN-induced acute liver injury.

\section{miR-149*-/- Mice Accelerate Liver Tumor Progression Induced by DEN}

To verify the function of miR-149* in HCC development, DEN-induced HCC incidence was compared in WT and miR$149^{*-I}$ mice. Mice were intraperitoneally injected with DEN on day 20 postpartum and then littermates were kept for 8 months. A significant difference of the liver tumor incidence can be observed after treatment with DEN in miR-149*-1mice (approximately 67\%) and WT mice (approximately $37 \%$ ) (Figure 2A). DEN-treated miR-149* ${ }^{-I-}$ mice had higher ALT and AST levels (approximately 2.9- and 1.9-fold for ALT and AST, respectively) than DEN-treated WT mice (Figure 2B). Hematoxylin and eosin staining was used to analyze the histopathologic changes of both WT and miR$14 *^{-/-}$mouse livers. The tumor regions of miR-149*-/livers presented focal necrosis, inflammation, and vacuolation due to cell damage (Figure 2C). In the area of the tumor tissues of miR-149*-l- mice, the normal liver architecture, such as bile duct and portal tract formation, was lost. To further address whether the deficiency of miR-149* promotes liver cell proliferation after DEN treatment, Ki-67 and proliferating cell nuclear antigen stainings were performed. The staining revealed that the deficiency of miR-149* in mice significantly enhanced liver cell positive staining in nontumor region of mouse liver after DEN administration (Figure 2, D and E), suggesting that the deficiency of miR-149* stimulated compensatory proliferation of hepatocytes after DEN treatment. Then, examination of the proinflammatory cytokine expression in tumor progression regulated by the NF- $\kappa \mathrm{B}$ signaling pathway revealed that DEN administration significantly up-regulated the mRNA levels of monocyte chemoattractant protein-1 (MCP-1), interferon- $\gamma$-induced protein 10, chemokine (C-C motif) ligand 5 (CCL5), and IL27 in miR$14 *^{-1-}$ mouse livers (Figure $2 \mathrm{~F}$ ). Overall, these data indicate that the deficiency of miR-149* promotes hepatocyte compensatory proliferation and liver carcinogenesis.

\section{miR-149* Mimics Repress Proliferation and Migration Abilities of Liver Cancer Cells}

There is growing evidence showing that cell proliferation and migration abilities are important key factors in the cancer-causing process. To address the biological significance of miR-149* in HCC development, real-time cellular analysis was performed to detect the effect of miR-149* mimics on proliferation and migration in Hepa1-6 liver cancer cells. Obviously, miR-149* mimics repressed Hepa1-6 cell growth (Figure 3A). Meanwhile, miR$149 *$-transfected cells showed a significant decrease in migration potential of Hepa1-6 cells (Figure 3B). Next, the transcription level of proliferation- and migration-associated inflammatory factors was determined. miR-149* mimic treatment in Hepa1-6 cells decreased gene expression levels of MCP-1, IL-1 $\beta$, IL-2, IL-10, IL-4, and MMP9 

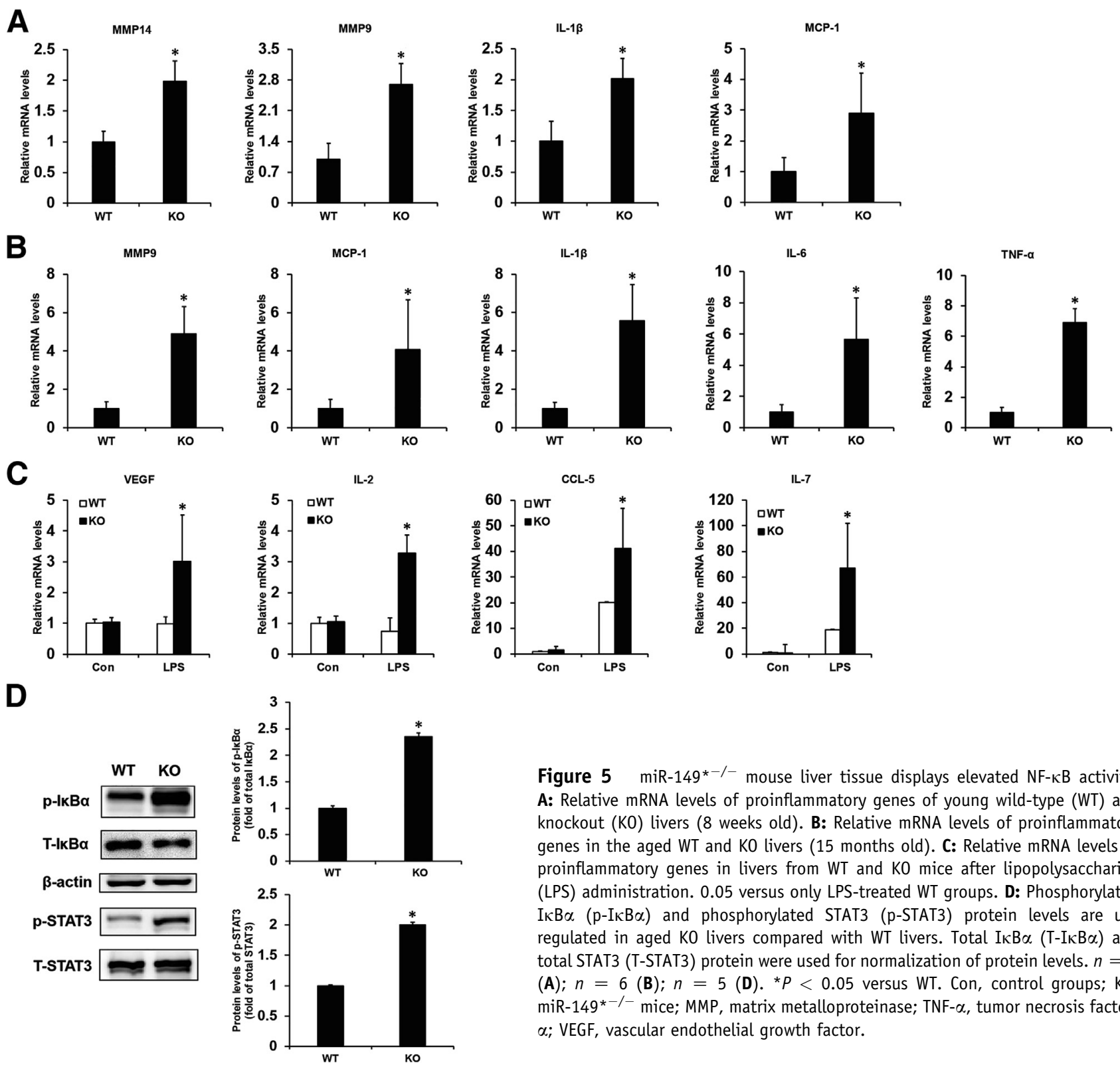

Figure 5 miR-149*-/- mouse liver tissue displays elevated NF- $\kappa B$ activity. A: Relative mRNA levels of proinflammatory genes of young wild-type (WT) and knockout (KO) livers ( 8 weeks old). B: Relative mRNA levels of proinflammatory genes in the aged WT and KO livers ( 15 months old). C: Relative mRNA levels of proinflammatory genes in livers from WT and KO mice after lipopolysaccharide (LPS) administration. 0.05 versus only LPS-treated WT groups. D: Phosphorylated I $\mathrm{B} \alpha(\mathrm{p}-\mathrm{I} \kappa \mathrm{B} \alpha)$ and phosphorylated STAT3 (p-STAT3) protein levels are up-

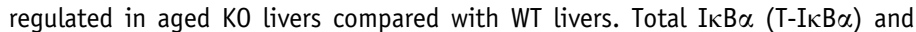
total STAT3 (T-STAT3) protein were used for normalization of protein levels. $n=7$ (A); $n=6$ (B); $n=5$ (D). ${ }^{*} P<0.05$ versus WT. Con, control groups; K0, miR-149*-/- mice; MMP, matrix metalloproteinase; TNF- $\alpha$, tumor necrosis factor$\alpha$; VEGF, vascular endothelial growth factor.

(Figure 3C). In contrast, miR-149* mimics had no inhibitory effect on cell proliferation of hepatocyte NCTC 1469 cells (Supplemental Figure S1A). In addition, miR-149* mimic treatment in NCTC 1469 cells showed significant inhibition of IL-4, IL-10, and MCP-1 expression, but not for CXCL-9, interferon- $\gamma$-induced protein 10 , CCL-5, IL-1 $\beta$, and MMP9 expression (Supplemental Figure S1B). These results suggest that miR-149* mimics impaired liver cancer cell proliferation and migration, resulting in suppressing liver tumor development.

\section{miR-149* Mimics Suppress Tumorigenesis in Vivo}

To further evaluate the function of miR-149* on tumor development in vivo, a xenograft tumor model was developed. The xenograft experiments showed lessened tumor sizes in miR-149* mimic-treated group than those in the NC mimic group (Figure 4, A and B). Moreover, the tumor mass was detected in each group, and the results showed that the tumor weight was significantly reduced in the miR149* mimic-treated group (Figure 4C). Thus, these results revealed that miR-149* mimics blocked the s.c. tumor formation induced by Hepa1-6 cells in vivo.

\section{miR-149*-/- Mouse Livers Display Elevated NF- $\kappa B$ Activity}

Livers from miR-149*-- mice have enhanced transcription levels of proinflammatory genes compared with WT controls. ${ }^{13}$ Herein, it was further shown that some NF$\kappa \mathrm{B}-$ mediated genes, such as MMP14, MMP9, IL-1 $\beta$, and MCP-1, showed higher expression levels in miR-149*-1- 

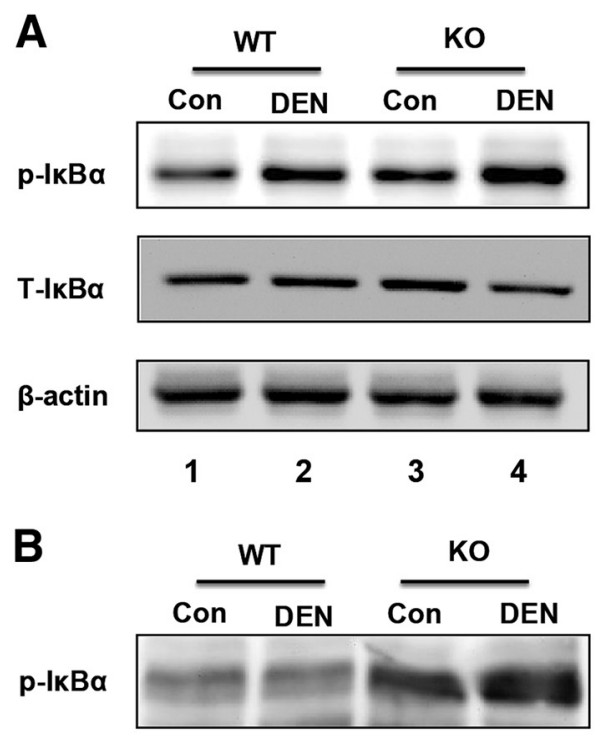

T-IkBa

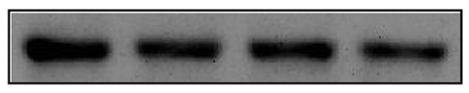

$\beta$-actin

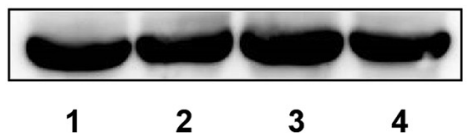

C

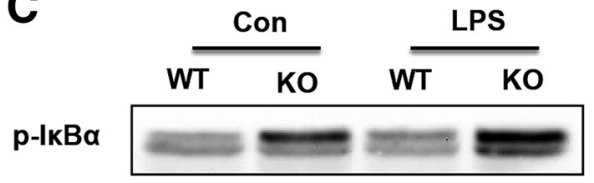

T-ІкB $\alpha$

$\beta$-actin
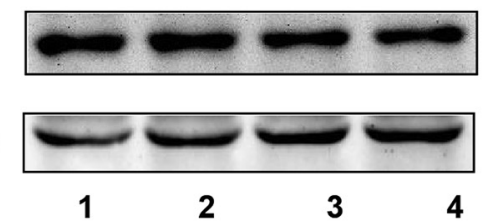
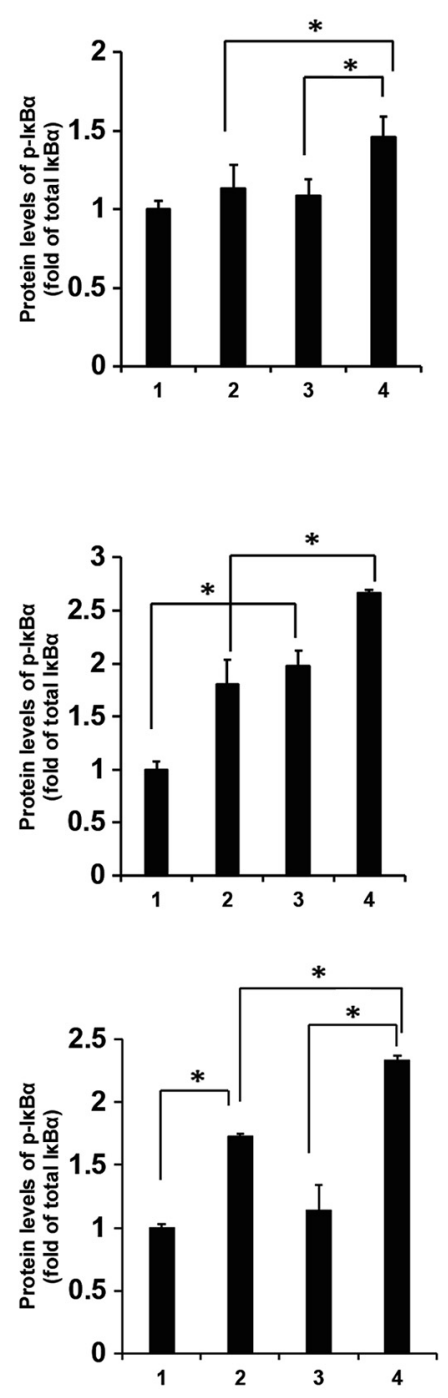

Figure 6 miR-149*-/- mouse livers are prone to activation of NF-KB induced by diethylnitrosamine (DEN) or lipopolysaccharide (LPS). A: The level of phosphorylated $\mathrm{I} \kappa \mathrm{B} \alpha(\mathrm{p}-\mathrm{I} \kappa \mathrm{B} \alpha)$ displays higher in knockout (KO) livers than that in wild-type (WT) livers after DEN treatment for 8 months. Total I $\mathrm{B} \alpha(\mathrm{T}-\mathrm{I} \kappa \mathrm{B} \alpha)$ was used for normalization of protein levels. B: $\mathrm{p}$-I $\mathrm{B} \boldsymbol{B} \alpha$ displays higher level in miR-149*-/- (KO) mouse livers than in WT livers in DEN-induced acute liver injury model (three independent experiments). T-I $\mathrm{B} \alpha$ was used for normalization of protein levels. C: $p-I \kappa B \alpha$ displays higher levels in $K 0$ mouse livers than in WT livers treated with LPS. T-I $\mathrm{B} \alpha$ was used for normalization of protein levels. $n=20$ to 25 (A); $n=7$ to 8 (B); $n=5$ (C). ${ }^{*} P<0.05$. Con, control groups. mouse livers than those in WT controls (Figure 5A). The aged miR-149*-/- mice had increased expression of MMP9, MCP-1, IL-6, IL-1 $\beta$, and TNF- $\alpha$ regulated by $\mathrm{NF}-\kappa \mathrm{B}$ (Figure $5 \mathrm{~B}$ ). In addition, the levels of some inflammatory cytokines mediated by $\mathrm{NF}-\kappa \mathrm{B}$ were significantly elevated in miR-149* ${ }^{-1-}$ mice after LPS administration, whereas these elevations were attenuated in WT mice (Figure 5C). Moreover, the phosphorylation levels of $\mathrm{I} \kappa \mathrm{B} \alpha$ and STAT3 were significantly elevated in the livers from miR-149*-/- aged mice (Figure 5D). The results collectively demonstrated that miR-149* may be an antagonist not only for the STAT3 signaling pathway but also for the $\mathrm{NF}-\kappa \mathrm{B}$ cell signaling pathway.

\section{miR-149*-/- Mouse Livers Are Sensitive to Activation of NF- $\kappa B$ Induced by DEN or LPS}

Constitutive activated NF- $\kappa \mathrm{B}$ signaling is often observed in multiple cancers, including liver cancer, and inspires a series of protumorigenic functions. ${ }^{31,33} \mathrm{NF}-\kappa \mathrm{B}$ activation in liver contributes to DEN-induced hepatocarcinogenesis. ${ }^{34,35}$ The deficiency of miR-149* resulted in 1.3- and 1.5-fold increment in $\mathrm{p}-\mathrm{I} \kappa \mathrm{B} \alpha$ level relative to WT group in response to DEN acute and long treatment, respectively (Figure 6, A and B). Similarly, miR-149* deficiency resulted in 1.37-fold higher $\mathrm{p}-\mathrm{I} \kappa \mathrm{B} \alpha$ level relative to WT mice after LPS treatment (Figure 6C). The results were also confirmed in male mice by using LPS treatment (Supplemental Figure S2). These results demonstrated one conceivable mechanism by which miR-149* suppressed HCC.

\section{miR-149* Antagonizes NF- $\kappa B$ Cell Signaling Pathway}

To test the hypothesis that miR-149* down-regulates NF- $\mathrm{B}$ cell signaling in cancer development, it was examined whether miR-149* mimics could suppress the level of $\mathrm{p}-\mathrm{I} \kappa \mathrm{B} \alpha$ in liver cancer cells. TNF- $\alpha$ was used to induce I $\mathrm{B} \alpha$ phosphorylation. TNF- $\alpha$ activated $\mathrm{I} \kappa \mathrm{B} \alpha$ phosphorylation 


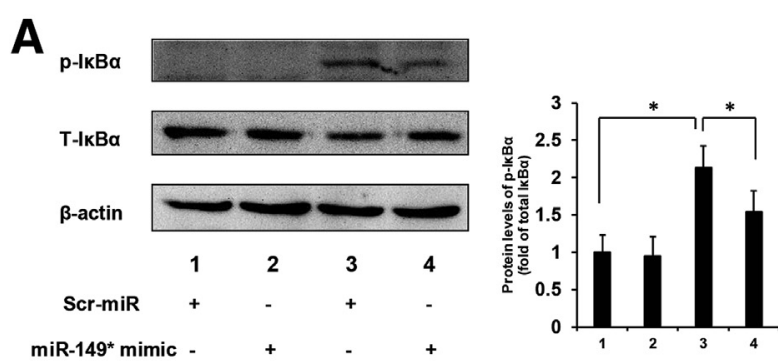

B

mTNF- $\alpha$

B
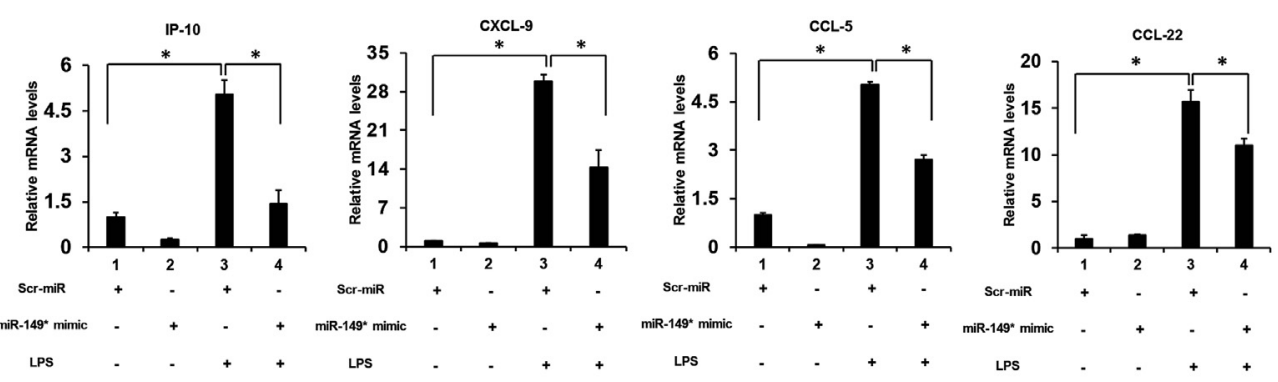

C
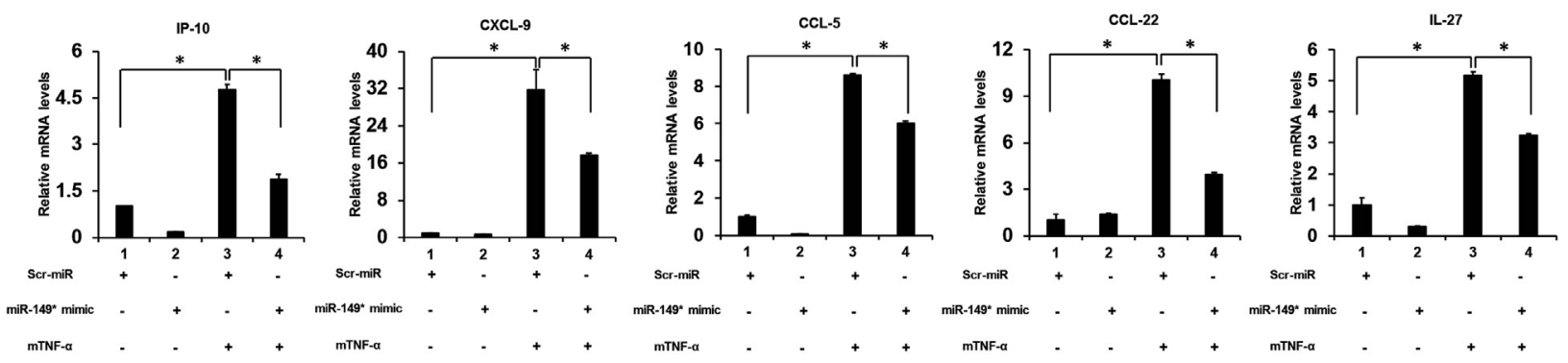

D
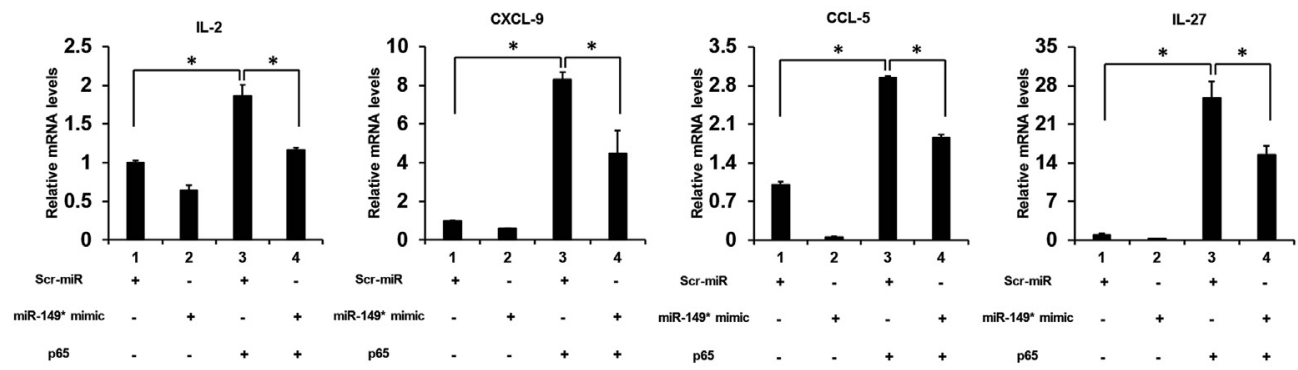

E
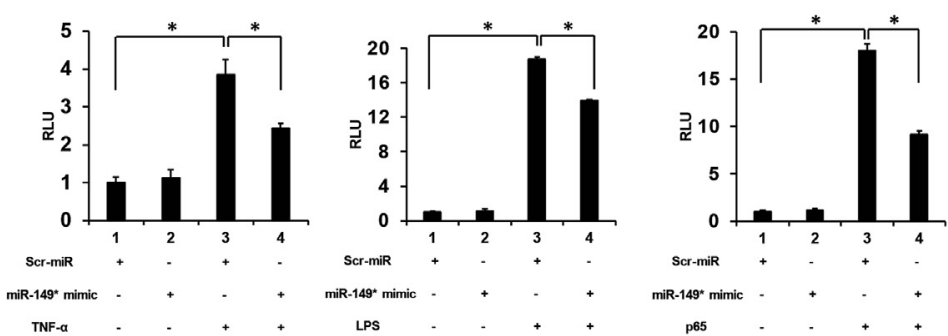

Figure 7 miR-149* suppresses the NF- $\kappa B$ cell signaling pathway. A: Phosphorylated $I \kappa B \alpha(p-I \kappa B \alpha)$ levels are decreased on induction of Hepa1-6 cells with tumor necrosis factor- $\alpha$ (TNF- $\alpha ; 20 \mathrm{ng} / \mathrm{mL}$ ) for 1 hour in cells after being transfected with miR-149* mimics compared with control mimics (Scr-miR). B: Relative mRNA levels of NF- $\kappa B$-mediated inflammatory cytokines induced by lipopolysaccharide (LPS) are reduced on miR-149* mimics. C: Relative mRNA levels of NF-KB-mediated inflammatory cytokines induced by murine TNF- $\alpha$ (mTNF $\alpha$ ) are decreased on miR-149* mimics. D: Relative mRNA levels of NF$\kappa B-$ mediated inflammatory cytokines induced by p65 overexpression are reduced on miR-149* mimics. E: miR-149* mimics lessen the luciferase signal of NFkB activity induced by LPS, TNF- $\alpha$, and p65 overexpression in Hepa1- 6 cells. $n=3$ (A-E). ${ }^{*} P<0.05$. CCL, chemokine (C-C motif) ligand; IP-10, interferon$\gamma$-induced protein 10; RLU, relative luciferase unit; $\mathrm{T}-\mathrm{I} \kappa \mathrm{B} \alpha$, total $\mathrm{I} \kappa \mathrm{B} \alpha$. 
significantly (Figure 7A). miR-149* mimics suppressed pI $\kappa$ B $\alpha$ stimulated by TNF- $\alpha$ by approximately $28 \%$ in Hepa16 cells (Figure 7A).

To investigate whether miR-149* has effects on the NF- $\kappa \mathrm{B}$ signaling, relative expression levels of proinflammatory genes in Hepa1-6 cells were determined by transfection of miR-149* mimics or NC mimics. The cells treated with miR-149* mimics showed the lower LPSinduced expression levels of interferon- $\gamma$-induced protein 10, CXCL9, CCL5, and CCL22 mRNAs than those of the NC mimic-treated cells (Figure 7B). A similar inhibition of expression of interferon- $\gamma$-induced protein 10, CXCL9, CCL5, and CCL22, and IL27 by miR-149* mimics was found after TNF- $\alpha$ stimulation (Figure $7 \mathrm{C}$ ). The p65 overexpression was also used to induce NF- $\kappa \mathrm{B}$ signaling to confirm these effects (Figure 7D).

Next, it was determined whether miR-149* mimics suppressed NF- $\kappa \mathrm{B}$ transcriptional activity. In luciferase assay, cells were treated with TNF- $\alpha$ or LPS, the two established NF- $\kappa B$ pathway activators, leading to 3.9- and 18.7-fold greater NF- $\kappa \mathrm{B}$ reporter activity, respectively (Figure $7 \mathrm{E}$ ). However, NF- $\kappa \mathrm{B}$ activity stimulated by TNF- $\alpha$ or LPS can be inhibited by miR-149* mimics. Moreover, to exclude the possibility that the compounds affected other signal pathways, p65 overexpression plasmid was transfected to activate the NF- $\kappa \mathrm{B}$ reporter. ${ }^{31,36}$ miR-149* mimics inhibited p65-induced NF- $\kappa B$ transactivity (Figure 7E). Moreover, p65 overexpression partially rescued the inhibitory effect of miR-149* mimics on Hepa1-6 cell proliferation (Supplemental Figure S3). All these findings support that miR-149* can antagonize NF- $\mathrm{BB}$ transactivity.

\section{miR-149* Regulates NF- $\kappa B$ Signaling by Targeting TRADD}

Next, to illuminate the molecular mechanism by which miR-149* modulated inhibition of NF- $\kappa \mathrm{B}$ signaling and then suppressed liver tumor carcinogenesis, the downstream targets of miR-149* were predicted using BiBiServ2-RNAhybrid (https://bibiserv.cebitec.uni-bielefeld.de/rnahybrid, last accessed December 22, 2018). ${ }^{37}$ TRADD, which can regulate the antiapoptotic effect of TNF- $\alpha$ by activating NF- $\kappa B$ signaling, ${ }^{38}$ may be a potential target of miR-149*. Furthermore, miR-149* mimics did not suppress the mRNA levels of $T R A D D$ in cells (data not shown) but decreased the protein expression of TRADD in Hepa1-6 cells (Figure 8A). It was further confirmed that miR-149* mimics inhibited the levels of TRADD protein by flow cytometry analysis (Supplemental Figure S4). Moreover, miR-149* agomir suppressed protein expression of TRADD in mouse liver (Figure 8B). In the Hepa1-6 cell-derived xenograft model, the protein levels of TRADD in the tumors induced by miR-149* mimic-transfected cells were lower than those in the tumors induced by NC mimic-transfected cells (Figure 8C), suggesting that miR-149* suppressed TRADD protein expression in vivo.
Although miR-149* mimics did not affect the endogenous mRNA levels of TRADD in Hepa1-6 cells, miR-149* mimics suppressed TRADD expression at the transcriptional level when TRADD was overexpressed in Hepa1-6 cells (Figure 8D). TRADD overexpression resulted in 1148.1-fold increase of mRNA levels compared with the control group, and mRNA levels of TRADD were significantly inhibited by miR-149* mimics (Figure 8D). It suggests that miR-149* may bind to the CDS of TRADD. Then, the complete CDS and two fragments of CDS of TRADD containing putative miR-149* binding sites were cloned into pMIRReport vector. miR-149* mimics significantly inhibited the luciferase activity of TRADD-luc containing complete CDS (Figure 8E). miR-149* mimics significantly downregulated the luciferase signal of TRADD-luc2 (putative miR-149*-binding site 2) but did not influence TRADDluc1 (putative miR-149*-binding site 1) (Figure 8E). Moreover, the luciferase activity with the mutated binding sites of TRADD was not affected by miR-149* mimics (Figure 8E). These results suggest that miR-149* suppressed TRADD protein expression, possibly through binding to the CDS of TRADD.

To evaluate the effect of TRADD on NF- $\kappa \mathrm{B}$ activity in Hepa1-6 cells, TRADD siRNA (siTRADD) was employed to knock down TRADD expression. Similar to the effects of miR-149* mimics, NF- $\kappa$ B activity, stimulated by TNF- $\alpha$, can be inhibited by siTRADD (Figure 8F). In addition, the expression of CXCL-1, CXCL-9, MCP-1, CCL-5, CCL-22, and IL-27, induced by TNF- $\alpha$, was significantly inhibited by siTRADD in Hepa1-6 cells (Figure 8G). These results suggested that the effects of TRADD knockdown were similar to those of miR-149* mimics for NF- $\kappa \mathrm{B}$ signaling and miR-149* may regulate NF- $\kappa \mathrm{B}$ signaling by targeting TRADD.

\section{Discussion}

HCC is a heterogeneous disease, and the HCC-related deaths are increasing. ${ }^{39}$ Growing investigations suggest that inflammation caused by liver injury drives hepatocarcinogenesis and understanding the molecular mechanism is a key direction in HCC research. DEN-mediated liver tumor development is a classic chemically induced HCC model in animals, and accumulating evidence shows that DEN-induced HCC in mice can be used to explore molecular mechanisms and identify novel therapeutic targets for repressing chemically induced hepatocarcinogenesis. ${ }^{40}$ The current study reveals that an inhibitory function of miR-149* in the pathogenesis of DEN-induced HCC is to reduce liver injury, inflammation, and liver carcinogenesis; and miR-149* mimics inhibited cellular proliferation and migration in HCC cells and liver cancer progression in a xenograft model. In addition, miR-149* can antagonize the NF- $\kappa B$ signaling pathway. Combining with previous findings, ${ }^{13}$ these results imply that miR-149* may 
A

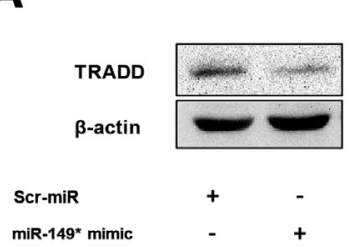

C

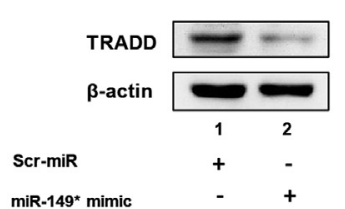

E

Mus musculus TRADD mRNA (NM_001033161)

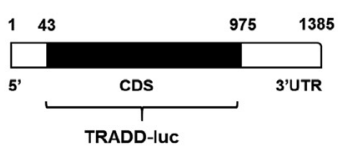

miR-149* mimic

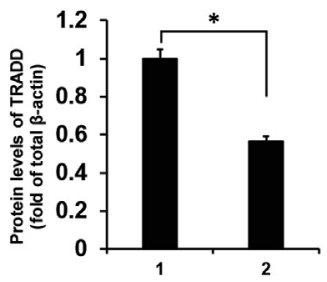

B
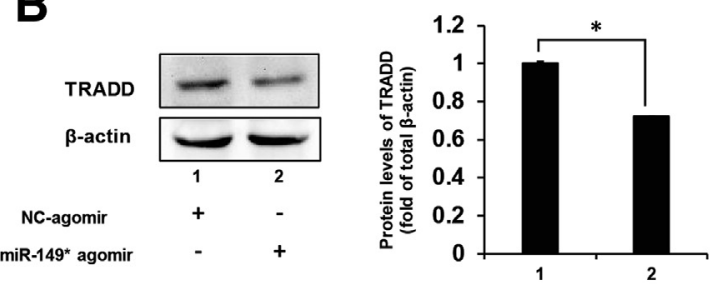

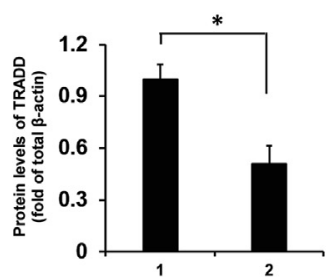

D

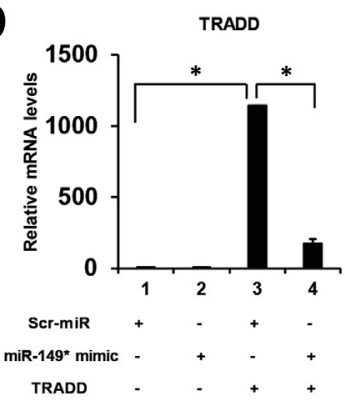

TRADD
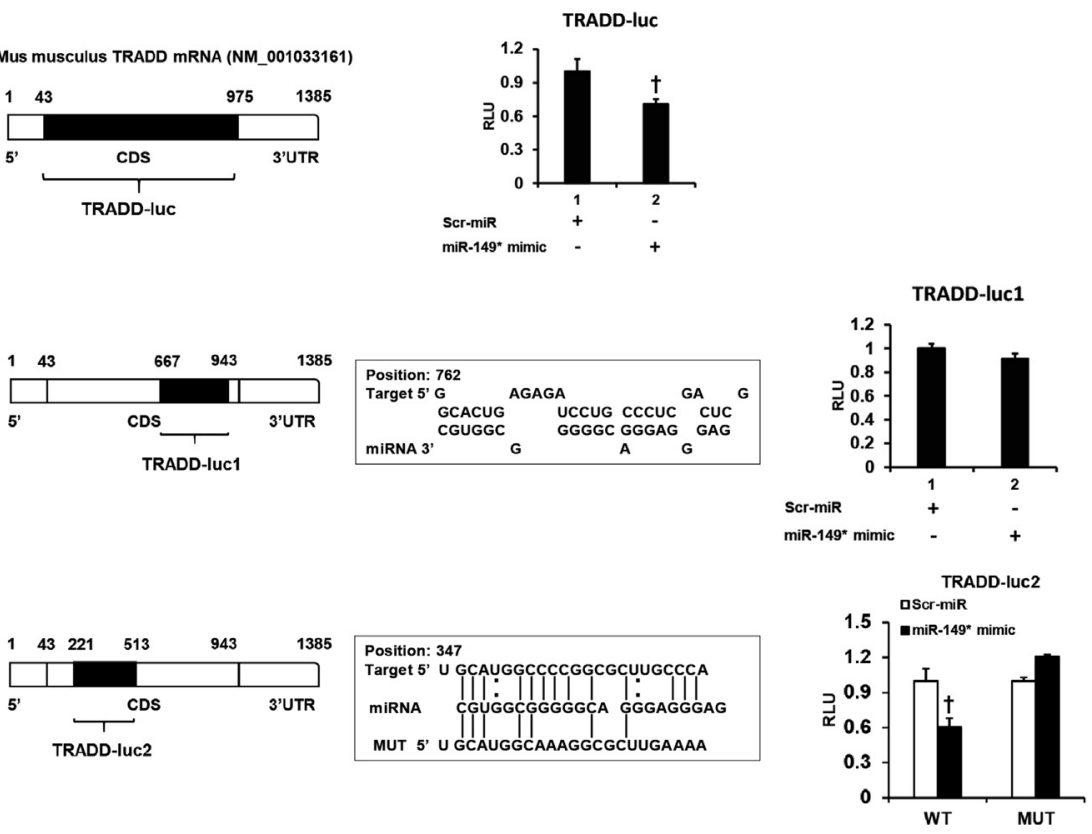

$\mathbf{F}$

G

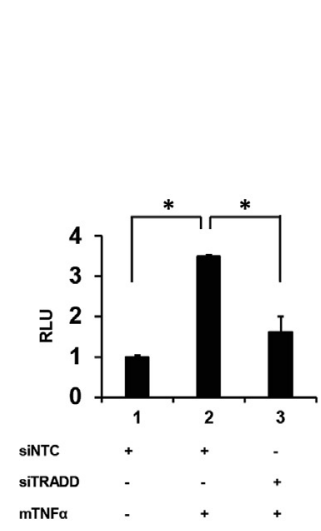

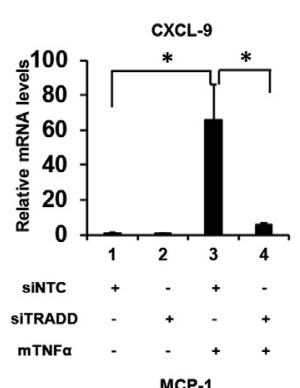

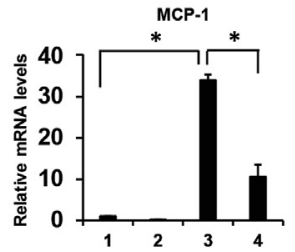

SiNTC

SITRADD

mTNFa
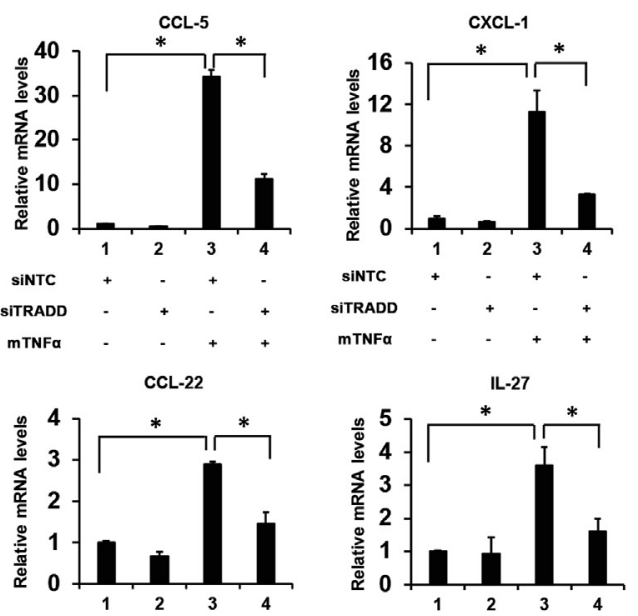

siNTC

SITRADD

mTNFa 
be a tumor suppressor in liver carcinogenesis via suppressing NF- $\kappa \mathrm{B}$ and STAT3 cell signaling pathways.

miRNAs have emerged as potential target molecules for anticancer therapy. miR-149* plays an oncogenic role in human melanoma through suppressing glycogen synthase kinase-3 $\alpha(\mathrm{GSK} 3 \alpha){ }^{23}$ miR-149* has previously been shown to directly target JunB, and thus promote cell growth and inhibit apoptosis in T-cell acute lymphoblastic leukaemia. ${ }^{41}$ Lin et al ${ }^{42}$ identified that miR-149* inhibits Akt1 and E2F1, leading to induction of apoptosis in human cancer cells. However, the physiological function of miR149* in liver carcinogenesis remains unidentified. Herein, it was shown that instead of playing an oncogenic role, miR$149^{*}$ is a potential suppressor in HCC development. miR149* may attenuate and suppress hepatic inflammation. The current data show that miR-149* may function as a tumor suppressor in HCC development by negatively regulating NF- $\kappa \mathrm{B}$ activation and its associated hepatic inflammatory responses.

The constitutive activation of NF- $\mathrm{KB}$ is involved in regulation of a variety of inflammatory diseases and tumors. ${ }^{43}$ Blocking the NF- $\kappa \mathrm{B}$ pathway can alleviate and even prevent disease development and deterioration. ${ }^{44,45}$ miR-149* has anti-inflammatory properties in vitro and in vivo. ${ }^{13}$ The present results reveal that miR-149* prevents the phosphorylation of I $\kappa \mathrm{B} \alpha$ and NF- $\kappa \mathrm{B}$ transactivity. Activation of NF$\kappa \mathrm{B}$ has been discovered to have oncogenic function in $\mathrm{HCC}$ via producing inflammatory cytokine IL-6 and other inflammatory responses, while blocking NF- $\mathrm{KB}$ obviously repressed pathogenesis of DEN-induced $\mathrm{HCC} .^{2}$ Therefore, the inhibition of NF- $\kappa \mathrm{B}$ might be a potential therapeutic strategy for treatment of liver cancer. This study revealed that miR-149* mimics strongly suppress NF- $\kappa \mathrm{B}$ cell signaling in liver cancer cells and the deletion of miR-149* is more susceptible to LPS- or DEN-stimulated NF- $\kappa \mathrm{B}$ activation in mouse liver. miR-149* antagonizes STAT3-induced liver inflammation. The aberrant STAT3 activation is frequently detected in various human carcinomas, including HCC. ${ }^{46-48}$ These reports suggest that miR-149* may function as a potential target and tumor suppressor to treat $\mathrm{HCC}$ via inhibiting activation of the NF- $\kappa \mathrm{B}$ and STAT3 pathway. The current data emphasize a major advantage of using an miRNA as a novel therapeutic strategy in HCC treatment because it simultaneously targets multiple signaling pathways.
TRADD plays different roles in participating in different biological processes, mainly including recruiting TNFinduced apoptosis and activating NF- $\mathrm{KB}$ and mitogenactivated protein kinase signaling by triggering tumor necrosis factor receptor 1 signaling. ${ }^{49}$ In TRADD-deficient human B lymphocytes, TRADD mediates activation of NF- $\kappa \mathrm{B}$ signaling and covers proapoptotic function. ${ }^{50}$ Pobezinskaya et $\mathrm{al}^{49}$ reported that deletion of TRADD in mice was more resistant to TNF, lipopolysaccharide, and poly(I:C)-induced toxicity and liver injury. Furthermore, miR-31 and miR-30c-2-3p may down-regulate TRADD expression, antagonize NF- $\kappa \mathrm{B}$ signaling, and contribute to the tumor suppression function in glioblastoma and breast cancer, respectively. ${ }^{38,51}$ This study shows that miR-149* mediates a tumor suppressor through antagonizing the TRADD/NF- $\kappa B$ pathway in liver cancer development. It was confirmed that miR-149* suppressed TRADD protein expression in vivo and in vitro, and that TRADD is required for TNF- $\alpha$-induced activation of NF- $\kappa \mathrm{B}$ signaling in Hepa1-6 cells.

The genetic deletion of miR-149* in mice may affect biogenesis and maturation of both miR-149 and miR-149* in miR-149*-1- mouse livers. The expression levels of both miR-149 and miR-149* were determined, and it was shown that the levels of both miRNAs were significantly reduced in miR-149*-- mouse livers (Supplemental Figure S5). Previous researchers have indicated that miR149 plays a tumor suppressive role in HCC development. ${ }^{52,53}$ To assess the role of miR-149 in the miR$149 *^{-1-}$ mice, the miR-149*-I- mice were injected with miR-149 agomir, before using DEN to induce acute liver injury. miR-149 agomir can partially reverse the DENinduced liver injury response in miR-149*-1- mice (Supplemental Figure S5), which suggests that the data shown in the genetic deletion of miR-149* in mice are due to the absence of both miR-149 and miR-149*.

In summary, we defined an essential and negative role for miR-149* in NF- $\kappa B$ signaling of liver carcinogenesis. The data demonstrated that miR-149* mimics or agomirs have utility in anticancer. Genetic deletion of miR-149* promotes liver inflammatory response and HCC development, thus establishing a foundation for evaluating miR-149* initiators as potential adjuvant therapies for inflammatory liver diseases and liver cancer.

\footnotetext{
Figure 8 miR-149* regulates NF-KB signaling by targeting TRADD. A: miR-149* mimics significantly decrease TRADD protein levels in Hepa1-6 cells. B: miR-149* agomir negatively regulates TRADD protein levels in mouse livers. C: miR-149* mimics have a suppression effect on TRADD protein levels in the xenograft tumors. D: miR-149* mimics significantly block mRNA levels of TRADD induced by TRADD overexpression. E: Hepa1-6 cells were transfected with luciferase expression plasmids containing complete coding sequence (CDS; (TRADD-luc) or two fragments of CDS (TRADD-luc1 and TRADD-luc2) of TRADD containing putative miR-149*-binding sites and either control miRNA (Scr-mimics) or miR-149* mimics. Then, luciferase activity was analyzed. miR-149* mimics significantly inhibited the luciferase activity of TRADD-luc containing complete CDS. And miR-149* mimics significantly down-regulate the luciferase signal of TRADD-luc2 (putative miR-149*-binding site 2) but do not significantly influence TRADD-luc1 (putative miR-149*-binding site 1) and TRADDluc2 with mutated (MUT) binding sites. F: Down-regulation of TRADD significantly inhibits NF- $\kappa B$ luciferase reporter activity induced by murine tumor necrosis factor- $\alpha$ (mTNF- $\alpha)$. After 24 hours of transfection, cells were stimulated with $\mathrm{mTNF}-\alpha(20 \mathrm{ng} / \mathrm{mL})$ for 6 hours and harvested. G: Relative mRNA levels of $\mathrm{NF}-\kappa \mathrm{B}$-mediated inflammatory cytokines induced by $\mathrm{mTNF}-\alpha(20 \mathrm{ng} / \mathrm{mL})$ are reduced on knockdown of TRADD. Cells were preplated into 6 -well plates and transfected with TRADD siRNA (siTRADD) $(50 \mathrm{nmol} / \mathrm{L})$ or siRNA negative control (siNTC). Then, the cells were induced by $\mathrm{mTNF}-\alpha(20 \mathrm{ng} / \mathrm{mL})$ for $6 \mathrm{hours}$ and harvested for RNA extraction. $n=3(\mathbf{E}-\mathbf{G}) .{ }^{*} P<0.05 ;{ }^{\dagger} P<0.05$ versus Scr-miR. CCL, chemokine (C-C motif) ligand; NC, negative control; RLU, relative luciferase unit; UTR, untranslated region; WT, wild type.
} 


\section{Acknowledgments}

We thank Dr. Akio Kruoda, Dr. Peter Tontonoz, Dr. Bruce Blumberg, and Xufeng Chen for plasmids.

\section{Supplemental Data}

Supplemental material for this article can be found at https://doi.org/10.1016/j.ajpath.2019.10.010.

\section{References}

1. Papaconstantinou I, Karakatsanis A, Gazouli M, Polymeneas G, Voros D: The role of microRNAs in liver cancer. Eur J Gastroenterol Hepatol 2012, 24:223-228

2. He G, Karin M: NF-kappaB and STAT3: key players in liver inflammation and cancer. Cell Res 2011, 21:159-168

3. Akinyemiju T, Abera S, Ahmed M, Alam N, Alemayohu MA, Allen $\mathrm{C}$, et al: The burden of primary liver cancer and underlying etiologies from 1990 to 2015 at the global, regional, and national level: results from the Global Burden of Disease Study 2015. JAMA Oncol 2017, 3:1683-1691

4. Jemal A, Bray F, Center MM, Ferlay J, Ward E, Forman D: Global cancer statistics. CA Cancer J Clin 2011, 61:69-90

5. Read SA, Douglas MW: Virus induced inflammation and cancer development. Cancer Lett 2014, 345:174-181

6. Greten FR, Eckmann L, Greten TF, Park JM, Li ZW, Egan LJ, Kagnoff MF, Karin M: IKKbeta links inflammation and tumorigenesis in a mouse model of colitis-associated cancer. Cell 2004, 118: 285-296

7. Pikarsky E, Porat RM, Stein I, Abramovitch R, Amit S, Kasem S, Gutkovich-Pyest E, Urieli-Shoval S, Galun E, Ben-Neriah Y: NFkappaB functions as a tumour promoter in inflammation-associated cancer. Nature 2004, 431:461-466

8. Yang F, Liu X, Liu Y, Liu Y, Zhang C, Wang Z, Jiang T, Wang Y: miR-181d/MALT1 regulatory axis attenuates mesenchymal phenotype through NF-kappaB pathways in glioblastoma. Cancer Lett 2017, 396:1-9

9. Kuhad A, Chopra K: Attenuation of diabetic nephropathy by tocotrienol: involvement of NFkB signaling pathway. Life Sci 2009, 84: 296-301

10. DiDonato JA, Mercurio F, Karin M: NF-kappaB and the link between inflammation and cancer. Immunol Rev 2012, 246:379-400

11. Lytle JR, Yario TA, Steitz JA: Target mRNAs are repressed as efficiently by microRNA-binding sites in the 5' UTR as in the 3' UTR Proc Natl Acad Sci U S A 2007, 104:9667-9672

12. Kumar A, Wong AK, Tizard ML, Moore RJ, Lefevre C: miRNA_ Targets: a database for miRNA target predictions in coding and noncoding regions of mRNAs. Genomics 2012, 100:352-356

13. Zhang Q, Su J, Wang Z, Qi H, Ge Z, Li Z, Chen WD, Wang YD: MicroRNA-149* suppresses hepatic inflammatory response through antagonizing STAT3 signaling pathway. Oncotarget 2017, 8: 65397-65406

14. Ng WL, Mohd Mohidin TB, Shukla K: Functional role of circular RNAs in cancer development and progression. RNA Biol 2018, 15: 995-1005

15. Wong CM, Tsang FH, Ng IO: Non-coding RNAs in hepatocellular carcinoma: molecular functions and pathological implications. Nat Rev Gastroenterol Hepatol 2018, 15:137-151

16. Fang JH, Zhang ZJ, Shang LR, Luo YW, Lin Y, Yuan Y, Zhuang SM: Hepatoma cell-secreted exosomal microrna-103 increases vascular permeability and promotes metastasis by targeting junction proteins. Hepatology 2018, 68:1459-1475
17. Kabir TD, Ganda C, Brown RM, Beveridge DJ, Richardson KL, Chaturvedi V, Candy P, Epis M, Wintle L, Kalinowski F, Kopp C, Stuart LM, Yeoh GC, George J, Leedman PJ: A microRNA-7/growth arrest specific 6/TYRO3 axis regulates the growth and invasiveness of sorafenib-resistant cells in human hepatocellular carcinoma. Hepatology 2018, 67:216-231

18. Wu H, Tao J, Li X, Zhang T, Zhao L, Wang Y, Zhang L, Xiong J, Zeng Z, Zhan N, Steer CJ, Che L, Dong M, Wang X, Niu J, Li Z, Yan G, Chen X, Song G: MicroRNA-206 prevents the pathogenesis of hepatocellular carcinoma by modulating expression of met protooncogene and cyclin-dependent kinase 6 in mice. Hepatology 2017, 66:1952-1967

19. Ell B, Mercatali L, Ibrahim T, Campbell N, Schwarzenbach H, Pantel K, Amadori D, Kang Y: Tumor-induced osteoclast miRNA changes as regulators and biomarkers of osteolytic bone metastasis. Cancer Cell 2013, 24:542-556

20. Scisciani C, Vossio S, Guerrieri F, Schinzari V, De Iaco R, D’Onorio de Meo P, Cervello M, Montalto G, Pollicino T, Raimondo G, Levrero M, Pediconi N: Transcriptional regulation of miR-224 upregulated in human HCCs by NFkappaB inflammatory pathways. J Hepatol 2012, 56:855-861

21. Zhang G, Chen L, Khan AA, Li B, Gu B, Lin F, Su X, Yan J: miRNA-124-3p/neuropilin-1(NRP-1) axis plays an important role in mediating glioblastoma growth and angiogenesis. Int J Cancer 2018, 143:635-644

22. Chafin CB, Regna NL, Caudell DL, Reilly CM: MicroRNA-let-7a promotes E2F-mediated cell proliferation and NFkappaB activation in vitro. Cell Mol Immunol 2014, 11:79-83

23. Jin L, Hu WL, Jiang CC, Wang JX, Han CC, Chu P, Zhang LJ, Thorne RF, Wilmott J, Scolyer RA, Hersey P, Zhang XD, Wu M: MicroRNA-149*, a p53-responsive microRNA, functions as an oncogenic regulator in human melanoma. Proc Natl Acad Sci U S A 2011, 108:15840-15845

24. German MA, Pillay M, Jeong DH, Hetawal A, Luo S, Janardhanan P, Kannan V, Rymarquis LA, Nobuta K, German R, De Paoli E, Lu C, Schroth G, Meyers BC, Green PJ: Global identification of microRNA-target RNA pairs by parallel analysis of RNA ends. Nat Biotechnol 2008, 26:941-946

25. Luo G, Chao YL, Tang B, Li BS, Xiao YF, Xie R, Wang SM Wu YY, Dong H, Liu XD, Yang SM: miR-149 represses metastasis of hepatocellular carcinoma by targeting actin-regulatory proteins PPM1F. Oncotarget 2015, 6:37808-37823

26. Xu K, Liu X, Mao X, Xue L, Wang R, Chen L, Chu X: MicroRNA149 suppresses colorectal cancer cell migration and invasion by directly targeting forkhead box transcription factor FOXM1. Cell Physiol Biochem 2015, 35:499-515

27. Ding H, Zheng S, Garcia-Ruiz D, Hou D, Wei Z, Liao Z, Li L, Zhang Y, Han X, Zen K, Zhang CY, Li J, Jiang X: Fasting induces a subcutaneous-to-visceral fat switch mediated by microRNA-149-3p and suppression of PRDM16. Nat Commun 2016, 7:11533

28. Yan Q, Jiang L, Liu M, Yu D, Zhang Y, Li Y, Fang S, Li Y, Zhu YH, Yuan YF, Guan XY: ANGPTL1 interacts with integrin alphalbetal to suppress HCC angiogenesis and metastasis by inhibiting JAK2/STAT3 signaling. Cancer Res 2017, 77:5831-5845

29. Yu H, Pardoll D, Jove R: STATs in cancer inflammation and immunity: a leading role for STAT3. Nat Rev Cancer 2009, 9:798-809

30. Committee for the Update of the Guide for the Care and Use of Laboratory AnimalsNational Research Council: Guide for the Care and Use of Laboratory Animals: Eighth Edition. Washington, DC, National Academies Press, 2011

31. Wang YD, Chen WD, Yu D, Forman BM, Huang W: The G-proteincoupled bile acid receptor, Gpbar1 (TGR5), negatively regulates hepatic inflammatory response through antagonizing nuclear factor kappa light-chain enhancer of activated B cells (NF-kappaB) in mice. Hepatology 2011, 54:1421-1432

32. Guo C, Qi H, Yu Y, Zhang Q, Su J, Yu D, Huang W, Chen WD, Wang YD: The G-protein-coupled bile acid receptor Gpbar1 (TGR5) 
inhibits gastric inflammation through antagonizing NF-kappaB signaling pathway. Front Pharmacol 2015, 6:287

33. Wang YD, Chen WD, Wang M, Yu D, Forman BM, Huang W: Farnesoid $\mathrm{X}$ receptor antagonizes nuclear factor kappaB in hepatic inflammatory response. Hepatology 2008, 48:1632-1643

34. Majumder S, Roy S, Kaffenberger T, Wang B, Costinean S, Frankel W, Bratasz A, Kuppusamy P, Hai T, Ghoshal K, Jacob ST: Loss of metallothionein predisposes mice to diethylnitrosamineinduced hepatocarcinogenesis by activating NF-kappaB target genes. Cancer Res 2010, 70:10265-10276

35. Yu LX, Yan HX, Liu Q, Yang W, Wu HP, Dong W, Tang L, Lin Y, He YQ, Zou SS, Wang C, Zhang HL, Cao GW, Wu MC, Wang HY: Endotoxin accumulation prevents carcinogen-induced apoptosis and promotes liver tumorigenesis in rodents. Hepatology 2010, 52: $1322-1333$

36. Zhou C, Tabb MM, Nelson EL, Grun F, Verma S, Sadatrafiei A, Lin M, Mallick S, Forman BM, Thummel KE, Blumberg B: Mutual repression between steroid and xenobiotic receptor and NF-kappaB signaling pathways links xenobiotic metabolism and inflammation. J Clin Invest 2006, 116:2280-2289

37. Rehmsmeier M, Steffen P, Hochsmann M, Giegerich R: Fast and effective prediction of microRNA/target duplexes. RNA 2004, 10: 1507-1517

38. Shukla K, Sharma AK, Ward A, Will R, Hielscher T, Balwierz A, Breunig C, Munstermann E, Konig R, Keklikoglou I, Wiemann S: MicroRNA-30c-2-3p negatively regulates NF-kappaB signaling and cell cycle progression through downregulation of TRADD and CCNE1 in breast cancer. Mol Oncol 2015, 9:1106-1119

39. Llovet JM, Augusto V, Anja L, Finn RS: Advances in targeted therapies for hepatocellular carcinoma in the genomic era. Nat Rev Clin Oncol 2015, 12:408-424

40. Weber A, Boege Y, Reisinger F, Heikenwalder M: Chronic liver inflammation and hepatocellular carcinoma: persistence matters. Swiss Med Wkly 2011, 141:w13197

41. Fan SJ, Li HB, Cui G, Kong XL, Sun LL, Zhao YQ, Li YH, Zhou J: miRNA-149* promotes cell proliferation and suppresses apoptosis by mediating JunB in T-cell acute lymphoblastic leukemia. Leuk Res 2016, 41:62-70

42. Lin RJ, Lin YC, Yu AL: miR-149* induces apoptosis by inhibiting Akt1 and E2F1 in human cancer cells. Mol Carcinog 2010, 49:719-727

43. Naugler WE, Karin M: NF-kappaB and cancer-identifying targets and mechanisms. Curr Opin Genet Dev 2008, 18:19-26
44. Wang C, Ke Y, Liu S, Pan S, Liu Z, Zhang H, Fan Z, Zhou C, Liu J, Wang F: Ectopic fibroblast growth factor receptor 1 promotes inflammation by promoting nuclear factor-kappaB signaling in prostate cancer cells. J Biol Chem 2018, 293: 14839-14849

45. Wu XY, Zhang CX, Deng LC, Xiao J, Yuan X, Zhang B, Hou ZB, Sheng ZH, Sun L, Jiang QC, Zhao W: Overexpressed D2 dopamine receptor inhibits non-small cell lung cancer progression through inhibiting Nf-KappaB signaling pathway. Cell Physiol Biochem 2018, 48:2258-2272

46. Yu H, Lee H, Herrmann A, Buettner R, Jove R: Revisiting STAT3 signalling in cancer: new and unexpected biological functions. Nat Rev Cancer 2014, 14:736-746

47. D’Amico S, Shi J, Martin BL, Crawford HC, Petrenko O, Reich NC: STAT3 is a master regulator of epithelial identity and KRAS-driven tumorigenesis. Genes Dev 2018, 32:1175-1187

48. Schulz-Heddergott R, Stark N, Edmunds SJ, Li J, Conradi LC, Bohnenberger H, Ceteci F, Greten FR, Dobbelstein M, Moll UM: Therapeutic ablation of gain-of-function mutant p53 in colorectal cancer inhibits Stat3-mediated tumor growth and invasion. Cancer Cell 2018, 34:298-314.e7

49. Pobezinskaya YL, Kim YS, Choksi S, Morgan MJ, Li T, Liu C, Liu Z: The function of TRADD in signaling through tumor necrosis factor receptor 1 and TRIF-dependent Toll-like receptors. Nat Immunol 2008, 9:1047

50. Schneider F, Neugebauer J, Griese J, Liefold N, Kutz H, Briseño C, Kieser A: The viral oncoprotein LMP1 exploits TRADD for signaling by masking its apoptotic activity. PLoS Biol 2008, 6:e8

51. Rajbhandari R, McFarland BC, Patel A, Gerigk M, Gray GK, Fehling SC, Bredel M, Berbari NF, Kim H, Marks MP, Meares GP, Sinha T, Chuang J, Benveniste EN, Nozell SE: Loss of tumor suppressive microRNA-31 enhances TRADD/NF- $\kappa \mathrm{B}$ signaling in glioblastoma. Oncotarget 2015, 6:17805-17816

52. Zhang Y, Guo X, Xiong L, Yu L, Li Z, Guo Q, Li Z, Li B, Lin N: Comprehensive analysis of microRNA-regulated protein interaction network reveals the tumor suppressive role of microRNA-149 in human hepatocellular carcinoma via targeting AKT-mTOR pathway. Mol Cancer 2014, 13:253

53. Dong J, Teng F, Guo W, Yang J, Ding G, Fu Z: lncRNA SNHG8 promotes the tumorigenesis and metastasis by sponging miR-149-5p and predicts tumor recurrence in hepatocellular carcinoma. Cell Physiol Biochem 2018, 51:2262-2274 